\title{
Analysis for the ARIANE BM1 and BM3 samples: nuclide inventory and decay heat
}

\author{
Dimitri Rochman*, Alexander Vasiliev, Hakim Ferroukhi, and Mathieu Hursin \\ Reactor Physics and Thermal hydraulic Laboratory, Paul Scherrer Institut, Villigen, Switzerland
}

Received: 19 August 2021 / Received in final form: 4 October 2021 / Accepted: 6 October 2021

\begin{abstract}
The Mixed Oxide samples (MOX) ARIANE Post Irradiation Examination samples BM1 and BM3 have been analyzed in this work, based on various two- and three-dimensional models. Calculated and measured nuclide inventories are compared based on CASMO5, SIMULATE and SNF simulations, and calculated values for the decay heat of the assembly containing the samples are also provided. For uncertainty propagation, the covariance information from three different nuclear data libraries are used. Uncertainties from manufacturing tolerances and operating conditions are also considered. The results from these two samples are compared with the ones from two $\mathrm{UO}_{2}$ samples, namely GU1 and GU3, also from the ARIANE program, applying the same calculation scheme and uncertainty assumptions. It is shown that a two-dimensional assembly model provides better agreement with the measurements than a two-dimensional single pin model, and that the full core three-dimensional model provides similar results compared to the assembly model, although no ${ }^{148} \mathrm{Nd}$ normalization is applied for the full core model. For the MOX assembly decay heat, as expected, heavy actinides have a higher contribution compared to the cases with the $\mathrm{UO}_{2}$ samples; additionally, decay heat uncertainties are moderately smaller in the case of the MOX assembly.
\end{abstract}

\section{Introduction}

The present analysis is the continuation of the multi-year effort started at the Paul Scherrer Institute (PSI) for a better understanding of the neutronics simulation capabilities of nuclear fuel. Such attempt is also related to the current studies performed in the European Union project called EURAD, and more specially its work package 8 [1], and within the current Coordinated Research Project (or CRP) on Spent Fuel Characterization from the IAEA [2]. As expressed in these international programs, there is a growing interest in knowing and understanding the level of confidence for the calculations of spent nuclear fuel characteristics, such as decay heat and nuclide inventory. Other neutronics-related quantities are also of interest, such as dose, but are not studied in this paper. The decay heat is an important quantity as it plays a keyrole in the design of canisters and geological repositories for long-term spent fuel storage, and nuclide inventory is directly linked to the risk of criticality of such canisters. These quantities are naturally changing with cooling time, and the considered decay scheme can influence calculated values at various storage periods.

\footnotetext{
*e-mail: dimitri-alexandre.rochman@psi.ch
}

Given the large number of spent nuclear fuels worldwide and the impracticability of systematically measuring their characteristics, the dependence on calculations is a necessity. Additionally, the use of Best Estimate Plus Uncertainties (or BEPU) for the spent fuel characterization implies reliable estimations of code biases, calculation uncertainties, and the range of applicability for such calculation scheme. Consequently, the present study fits within this framework and proposes an analysis of two Post Irradiation Examination samples, called BM1 and BM3, in terms of nuclide inventory and decay heat. The concentrations for a limited number of isotopes are reported for these samples, and the decay heat (for the samples or for their hosting assembly) was not measured. The detailed characteristics of such samples can be found in the public report of the ARIANE program [3] and in the SFCOMPO database [4]. Very similar works were recently performed for the GU1 and GU3 samples (same simulation process and same uncertainty method) $[5,6]$. These two samples are made of $\mathrm{UO}_{2}$ fuel, whereas the BM1 and BM3 samples are made of Mixed OXyde (or MOX); the analysis of these four samples will eventually lead to more general conclusions regarding decay heat and nuclide concentration calculations based on the CASMO5, SIMULATE and SNF codes [7-9]. Whereas these samples were primarily selected for the validation of the calculated isotopic 
composition, the decay heat was also calculated, but not compared to measured values, as there was no measured decay heat for these samples. In addition, calculated decay heat uncertainties are also obtained, but they cannot be compared to experimental values.

This study is structured similarly to the studies of the GU1 and GU3 samples: first details of the samples are given, followed by the irradiation simulations, analysis and general remarks. A number of numerical results are not directly included in the sections of this paper, but can be found in Appendix.

\section{The BM1 and BM3 samples}

\subsection{Samples, assembly and irradiation history}

The BM1 and BM3 samples are two distinct MOX samples, irradiated in the Swiss Beznau power plant (called KKB1) from July 1988 to April 1993 (1422 effective full power days and 234 intercycle shutdown days), during five consecutive cycles (cycle 18-22); details can be found in the ARIANE report [3]. These samples were located in the same assembly, called M109, at the same vertical nodal elevation, but in different fuel rods, see Figure 1. The reported burnup values are 47.0 and $48.5 \mathrm{MWd} / \mathrm{kgHM}$ for BM1 and BM3, respectively. The M109 $14 \times 14$ assembly was made of rods with three different types of plutonium $(\mathrm{Pu})$ vectors (with respect to the wt.\% of total $\mathrm{Pu}$ in $\mathrm{U}+\mathrm{Pu}+\mathrm{Am}$ ): $2.36 \%$, or low (white boxes in Fig. 1), $2.99 \%$ or medium (light gray boxes) and $4.25 \%$ or high (dark gray boxes at the side of the assembly). The BM1 and BM3 samples were located in rods with a low concentration of $\mathrm{Pu}$; the isotopic composition of the fresh rods in wt.\% was 1.11 for ${ }^{238} \mathrm{Pu}, 61.31$ for ${ }^{239} \mathrm{Pu}, 23.59$ for ${ }^{240} \mathrm{Pu}$, 8.72 for ${ }^{241} \mathrm{Pu}, 4.16$ for ${ }^{242} \mathrm{Pu}$ and finally 1.10 for ${ }^{241} \mathrm{Am}$.

They were located at a vertical position corresponding to $213 \mathrm{~cm}$ from the top of the active fuel. As seen in the figure, both samples were close to a water channel and close to rods with different $\mathrm{Pu}$ concentrations. For the present analysis, the irradiation history for this assembly is not extracted from the ARIANE report, but directly from the PSI database called CMSYS. Such database is normally used for core licensing calculations for the Swiss regulator, and contains all detailed information regarding reactor cycle operations and conditions, necessary for CASMO5 and SIMULATE simulations; interested readers can find more information in references [10-17]. Generally, the PSI database contains a more detailed irradiation history compared to the ARIANE report, with variations of boron concentrations and temperatures at every irradiation step. Additionally, the characteristics of all assemblies in the core for the cycles of interest are known, leading to study the effect of neighboring assemblies: see Figure 2 which indicates the locations of the assembly M109 during cycles 18 to 22, as well as the heterogeneous assembly burnup distributions. The assembly is moved from cycle to cycle, experiencing variations in neutron fluence and power. Such information is obtained from the combination of calculations from CASMO5 and the core

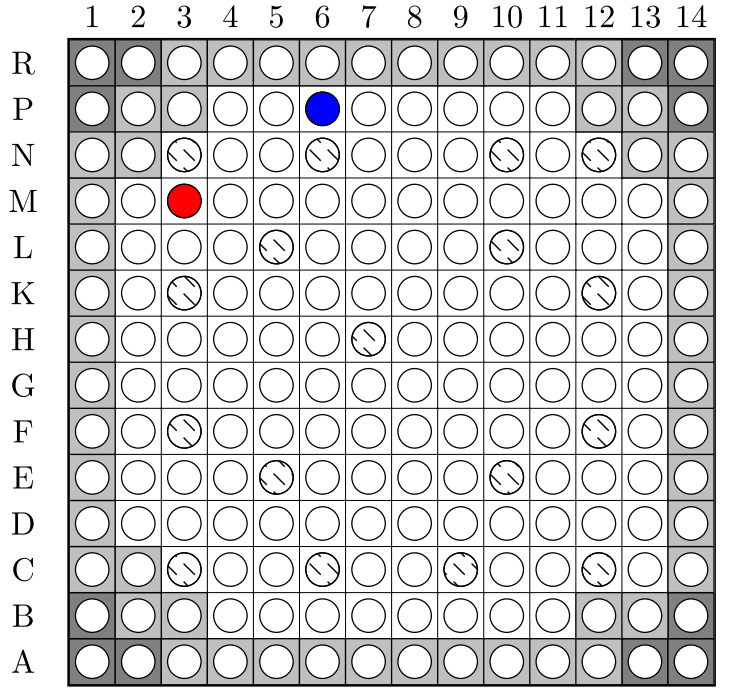

Fig. 1. Radial locations of the rods containing the BM1 (red) and BM3 (blue) samples in the assembly M109. The variations of gray represent different $\mathrm{Pu}$ enrichments. Water channels are indicated by dashes circles.

simulator SIMULATE. At the end of cycle 22, the calculated average assembly burnup is about $39.1 \mathrm{MWd} / \mathrm{kgHM}$, and the segment burnup containing the samples is about 43.6 MWd/kgHM.

\section{$2.2 \mathrm{BM} 1$ and $\mathrm{BM} 3$ measurements}

The ARIANE report is the source of information for the measured nuclide concentrations of the BM1 and BM3 samples. All concentrations used in the present work are reported in appendix of this paper (Tab. B.1), and were extracted from the ARIANE report in the units of $\mathrm{mg} / \mathrm{gU}$. In the cases of nuclides with concentrations in both the solution and the residues, the sum of these quantities is used.

Aliquots of the BM1 sample were analyzed in two different laboratories: PSI and SCK-CEN (Mol, Belgium), and are referred to as " $B M 1-P$ " and " $B M 1-S$ " in this work (and in the ARIANE report), respectively. The nuclide measurements for BM1-P happen between 5 and 7 years after the end of cycle 22, whereas for BM1-S, the measurement period was between 4 and 7 years. Looking carefully at the measured values for BM1-P and BM1-S, there are a number of cases where differences between values exceed many reported standard deviations (see Tab. B.1): ${ }^{238-241} \mathrm{Pu}$, ${ }^{244,245} \mathrm{Cm},{ }^{103} \mathrm{Rh},{ }^{125} \mathrm{Sb},{ }^{134,135} \mathrm{Cs},{ }^{147} \mathrm{Sm},{ }^{151,155} \mathrm{Eu}$ and ${ }^{155} \mathrm{Gd}$. Some comments are provided in the ARIANE report, regarding these experimental values: the ${ }^{137} \mathrm{Cs}$ concentration is out of trend for BM1-P, all Cs concentrations present overpredictions for BM1-P, and some $\mathrm{Eu}$ uncertainties are underestimated for BM1-P. Regarding U and $\mathrm{Pu}$ concentrations, the ARIANE report mentions that "It is agreed to discard the Pu absolute contents measured by PSI, assuming the high quality of the SCK-CEN TIMS results". For the present study, both samples are compared with calculated values, but the study on the calculated 


\section{Cycle 18 EOC}

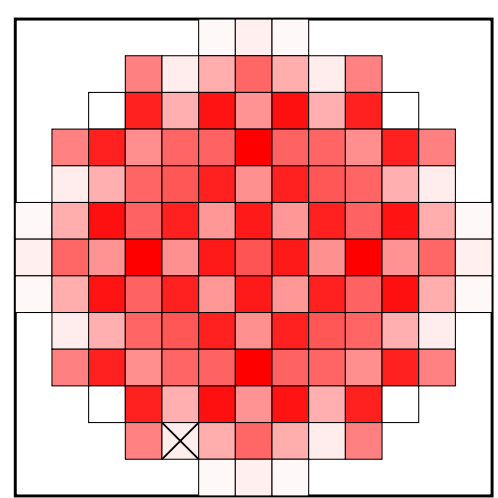

Cycle 21 EOC

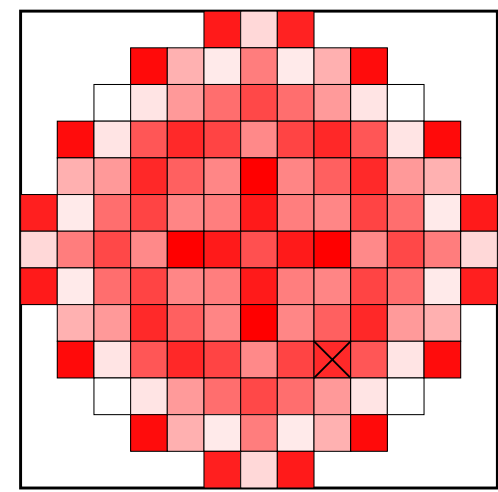

Cycle 19 EOC

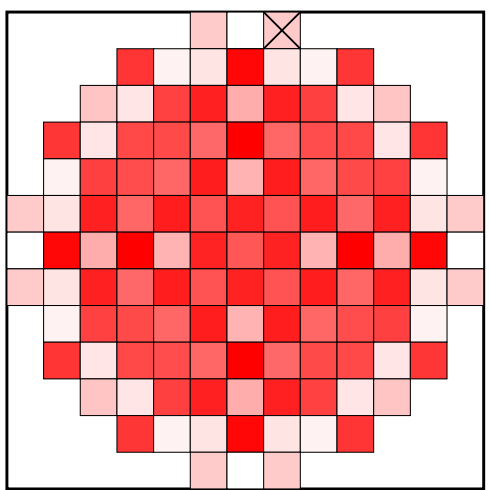

Cycle 22 EOC

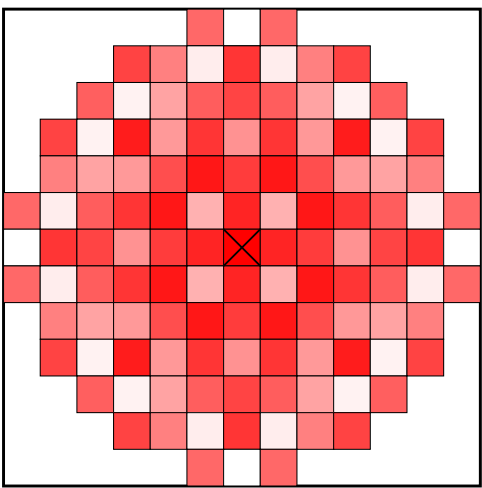

Fig. 2. Locations of the assemblies M109 (cycles 18-22) containing the BM1 and BM3 samples. The positions of M109 are indicated by a cross. The colors are proportional to the assembly burnup obtained from SIMULATE-3 at the end of each cycle (EOC): white for low burnup and dark red for high burnup values.

uncertainties presented later is arbitrary performed with the BM1-P sample (the inputs to the codes are the same for both samples, except for the cooling periods after irradiation). Regarding ${ }^{148} \mathrm{Nd}$, distinct values are provided for BM1-P and BM1-S, which differ by $2.5 \%$. Such difference is smaller than the reported experimental uncertainty for the BM1-P case (5\%), but larger than for the BM1-S case $(0.3 \%)$. As ${ }^{148} \mathrm{Nd}$ is used to calculate the sample burnup with the two-dimensional models, two burnup values will be obtained (one for BM1-P and one for BM1-S).

For the BM3 sample, only one set of measurements was performed (from PSI), without experimental uncertainties. Due to the poor mass balance (as in the case of the GU1 sample [5]), only measurements for a small number of isotopes were retained: 9 actinides ( $\mathrm{U}$ and $\mathrm{Pu}$ ), and $7 \mathrm{Nd}$ isotopes (see Tab. B.2); concentrations were adjusted by a factor 0.72 in the ARIANE report, to compensate for the mass balance. In the following, comparisons with calculated concentrations will be presented, but without detailed analysis.

\section{Simulation tools and calculation schemes}

The simulation tools used in modelling these samples and their irradiation are similar to the ones for the studies of the GU1 and GU3 samples [5,6].

\subsection{Nominal simulations}

All nominal calculations (without uncertainties) were performed with the deterministic code CASMO5 for the two-dimensional calculations. Results are presented in different figures and tables, both for single pin calculations and for a full assembly.

Additionally, three-dimensional full-core calculations are performed, similar to the GU1 sample study, using combinations of CASMO5 (lattice code), SIMULATE (core simulator) and the SNF (for decay heat and radiation calculations) codes. A summary of the various combinations of codes is provided below (all libraries CASMO5 contain 586 energy groups):

- CASMO5 version 2.03.00, with the nuclear data library based on the US ENDF/B-VII.1 original library, called version "e7r1.201.586.bin", or e7.201 in short,

- same with CASMO5 version 2.13.00,

- CASMO5 version 2.13.00, with an updated processed library version, called "e7r1.202.586.bin" (202 instead of 201), and also based on ENDF/B-VII.1, or e7.202 in short.

- CASMO5 version 2.03.00, with e7r1.201.586.bin, SIMULATE-3 version 6.07.17_MOX_4 and SNF version 1.6.4, (called in short 3D-1 in the following), 
D. Rochman et al.: EPJ Nuclear Sci. Technol. 7, 18 (2021)

- CASMO5 version 2.13.00, with e7r1.201.586.bin, SIMULATE-3 version 6.07.17_MOX_4 and SNF version 1.6.4, (called 3D-2) and

- CASMO5 version 2.13.00, with e7r1.202.586.bin, SIMULATE5 version 1.16 .00 and SNF version 1.07 (called 3D-3). This SNF version is posterior to the 1.6.4 version and allows to calculate concentrations for a larger number of isotopes.

Concerning the description of the irradiation history and of the assembly characteristics, details were previously provided: as mentioned, the irradiation history comes from the PSI internal database and not from the ARIANE report; the main difference concerns the time step division and the denser information for the variation of reactor parameters: whereas 8 to 16 steps are provided in the ARIANE report per cycle, a total of 73 irradiation steps are considered in the present assembly and full core models. Additionally, as the two-dimensional model (2D) for the full assembly is derived from the core simulator (3D) based on an in-house procedure called BOHR [12], it ensures consistency of parametrizations between the 2D assembly and 3D models. In the case of the single pin 2D model, it is obtained from reference [18]. This pin model considers a simplified irradiation scheme, and the pin cell is divided in seven radial rings.

These models are used in the following to obtain various $\mathrm{C} / \mathrm{E}$ ratios for nuclide densities (Calculated over Experimental values), calculated decay heat, as well as uncertainties from the variations of model parameters and nuclear data (only in the case of the 2D assembly and 3D-1 calculations).

\subsection{Uncertainty propagation}

The same approach as for the GU1 and GU3 samples is followed in the following. The uncertainty propagation is performed applying random variations to a selection of inputs; all probability density functions are normal unless otherwise mentioned, and the term "uncertainty" is equal to one standard deviation $(1 \sigma)$. Although the uncertainty propagation is performed for both samples BM1 and BM3, the results presented here are for BM1(-P) only.

Solely the version 2.03 for CASMO5 is used for the propagation of uncertainties for the $2 \mathrm{D}$ pin and assembly cases. For the full core, only the case called 3D-1 is considered, which is also based on CASMO5 version 2.03 (with the addition of SIMULATE and SNF). The uncertainties on nuclide densities and on decay heat are obtained by repeating $n$ times the same calculations, with specific random inputs. $n$ varies between 300 and 1000, depending on the case considered. For instance, for the pin simulation, 1000 calculations are performed with random nuclear data. For the full core and 2D assembly calculations, 300 cases are considered.

For the full core calculations, a large number of different assemblies are considered, with all their specific segments (one segment is equivalent to one CASMO5 calculation). In total, 18 segments and 7 cycles (from cycle 16 to 22) are calculated 300 times, each time with a specific set of random nuclear data or random parameters. Only
300 iterations could be done, given the substantial required calculation time.

Concerning the types of varied data, nuclear data, operating conditions, and manufacturing tolerances, were sampled. The uncertainties obtained for this sample can be directly compared to the ones for GU1 and GU3, as the same assumptions and methods were applied. Additional details can be found in reference [5], and a summary is provided here. In terms of nuclear data, as presented in the following figures and tables, the covariance information given in three libraries are separately used: ENDF/B-VIII.0, JEFF-3.3 and JENDL-4.0 [19-21], using the in-house tool SHARK-X [22]. These covariance files contain both uncertainties and correlations mainly for cross sections, nubar and fission spectra. It can be noticed that the nominal library is different than the covariance libraries. This introduces an inconsistency between nominal values, uncertainties and correlations. Such drawback was accepted given that the current interest was on the effect of the latest covariance libraries, provided that only the ENDF/B-VII.1 library was validated at PSI. For fission yields, only uncertainties are provided in the libraries, and an in-house method is used to introduce a limited number of correlations (see Refs. [23-25]). It mainly consists in adding correlations due to the overall normalization of the independent fission yields to $200 \%$, as well as considering relationships for specific mass chains (mass conservation), charge conservation and complementary fission products. Uncertainties from decay data (such as half-lives, branching ratios) are not propagated in the present work, which can lead to an underestimation of the decay heat uncertainty. Together with the simultaneous variations of all nuclear data, the effects of fission yields (called FY in the following) and of the rest of nuclear data (called XS for cross sections, nubar and fission spectra) are also calculated by varying them separately. Such individual effects are obtained only for the $2 \mathrm{D}$ assembly case. Additionally, for a limited number of important isotopes (main actinides such as ${ }^{239,241} \mathrm{Pu}$ or ${ }^{235,238} \mathrm{U}$ ), their individual effects are also studied. Results are presented in the following sections.

For other parameters, the following cases are considered with uniform distributions: fuel and moderator temperatures (called TFU and TMO, with a standard deviation of $2 \%$ ), boron concentration (called BOR, with a standard deviation of $2 \%$ ), the burnup value of each depletion step (called DEP, with a standard deviation of $0.25 \%$ ), and finally the pin radii (RAD), the pin position in the $\mathrm{X}$ and $\mathrm{Y}$ directions (X-Y), the fuel density and ${ }^{239} \mathrm{Pu}$ enrichment (called DEN+ENR) and the pin pitch (PITCH) are varied with a standard deviation of $0.5 \%$. These variations are based on expert judgment and were also applied in previous the published studies for the GU1 and GU3 samples. These variations are separately propagated to the quantities of interest and are presented in the next sections and tables. It can be noted that their global effect might not be the linear sum of their variances, as observed in references [13,17].

Based on these assumptions and models, results are presented in the next sections. As many tabulated results 

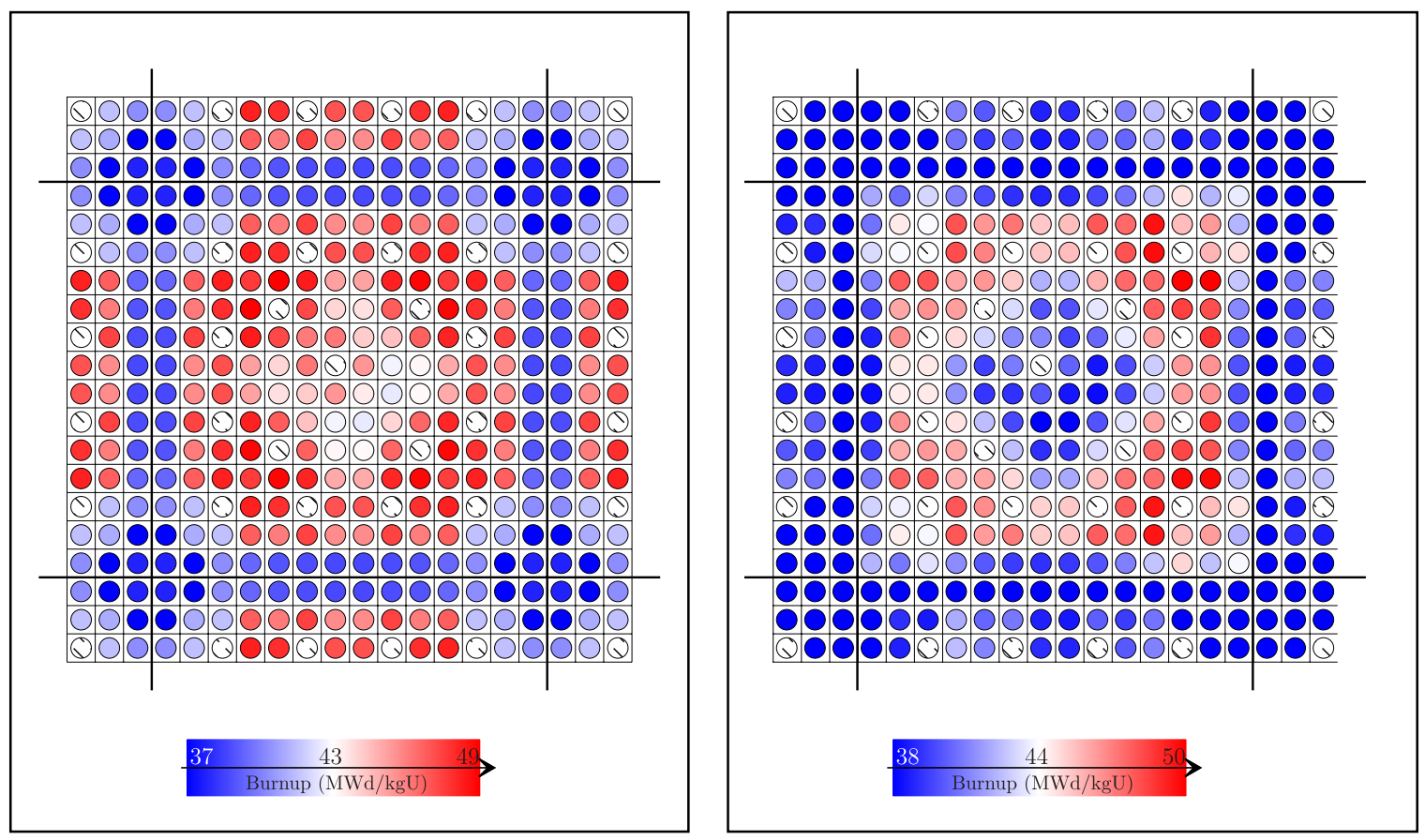

Fig. 3. Rod burnup distributions for the assembly M109 (and neighbors) and segment 6 containing the BM1 and BM3 samples at the EOC for cycle 22. Left: CASMO5 values; right: SIMULATE-3 values.

are also given, tables for numerical values can be found in appendix.

\section{Sample burnup values}

The sample burnup values can be obtained from the above calculations, and eventually being adjusted to match the measured ${ }^{148} \mathrm{Nd}$ content. It is not a measured quantity, but it is convenient for comparison to other samples, spent fuel characterization, or safeguard applications. The burnup step adjustment can be done only for the $2 \mathrm{D}$ calculations so that the measured and calculated ${ }^{148} \mathrm{Nd}$ concentrations coincide, whereas in the $3 \mathrm{D}$ case, none of the parameters are modified (e.g. core power, cycle lengths). Because of the boundary conditions and calculation scheme, different burnup values are expected between the $2 \mathrm{D}$ and $3 \mathrm{D}$ calculations. Such differences are highlighted in Figure 3 for the assembly M109 and the surrounding ones (using reflective boundaries in the case of the $2 \mathrm{D}$ calculations). As observed, the pin burnup distributions are not the same, as well as the average segment value (indicated by both scales below the figures). Apart from the differences in the neighboring assemblies, the rod burnup values for the central part are sensibly different. This moderately affect the BM1 and BM3 samples, as their rods are close to the side of the assembly.

There are many possibilities to calculate the sample burnup, solely based on the method of normalization (without or to one of the measured ${ }^{148} \mathrm{Nd}$ contents), the considered geometry (single pin or assembly in 2D, or full $3 \mathrm{D}$ core), and the code and library versions; results are gathered in Table 1. Without doubt, the sample burnup values are not unambiguously known. Other values can be found in the literature, which contribute to such dispersion [3,26,27]. Compared to the trend of the ${ }^{148} \mathrm{Nd}$ measured concentrations (last line of Tab. 1), differences are observed when comparing average burnup values. This comes from the fact that the calculated burnup profile is slightly opposite to the one experimentally observed between BM1 and BM3. This should nevertheless be balanced by the experimental uncertainties, as well as by the calculated dispersion, and also by the calculated uncertainties being above $1 \%$ (see the next sections).

Finally, the sample burnup values are in the vicinity of 47-47.5 MWd/kgHM for BM1, and of 47 for BM3. It is certainly not reasonable to quote calculated values with a better precision than $1-3 \%$.

\section{Post irradiation examination results}

As presented earlier, the nuclide concentrations are calculated considering three different types of geometries and environments. Comparisons of the results, in terms of $\mathrm{C} / \mathrm{E}$ and uncertainties are presented in this section.

\subsection{Nominal calculations}

The $\mathrm{C} / \mathrm{E}$ values for calculations of the BM1-P samples are presented in Figure 4, for different geometries and with different code versions. In appendix, similar figures for the BM1-S and BM3 samples can be found (Figs. A.1 and A.2). Tabulated values for these comparisons are given in Tables B.3, B.4 and B.5. A summary in terms of average $\mathrm{C} / \mathrm{E}$ is given in Table 2. The first remark is 

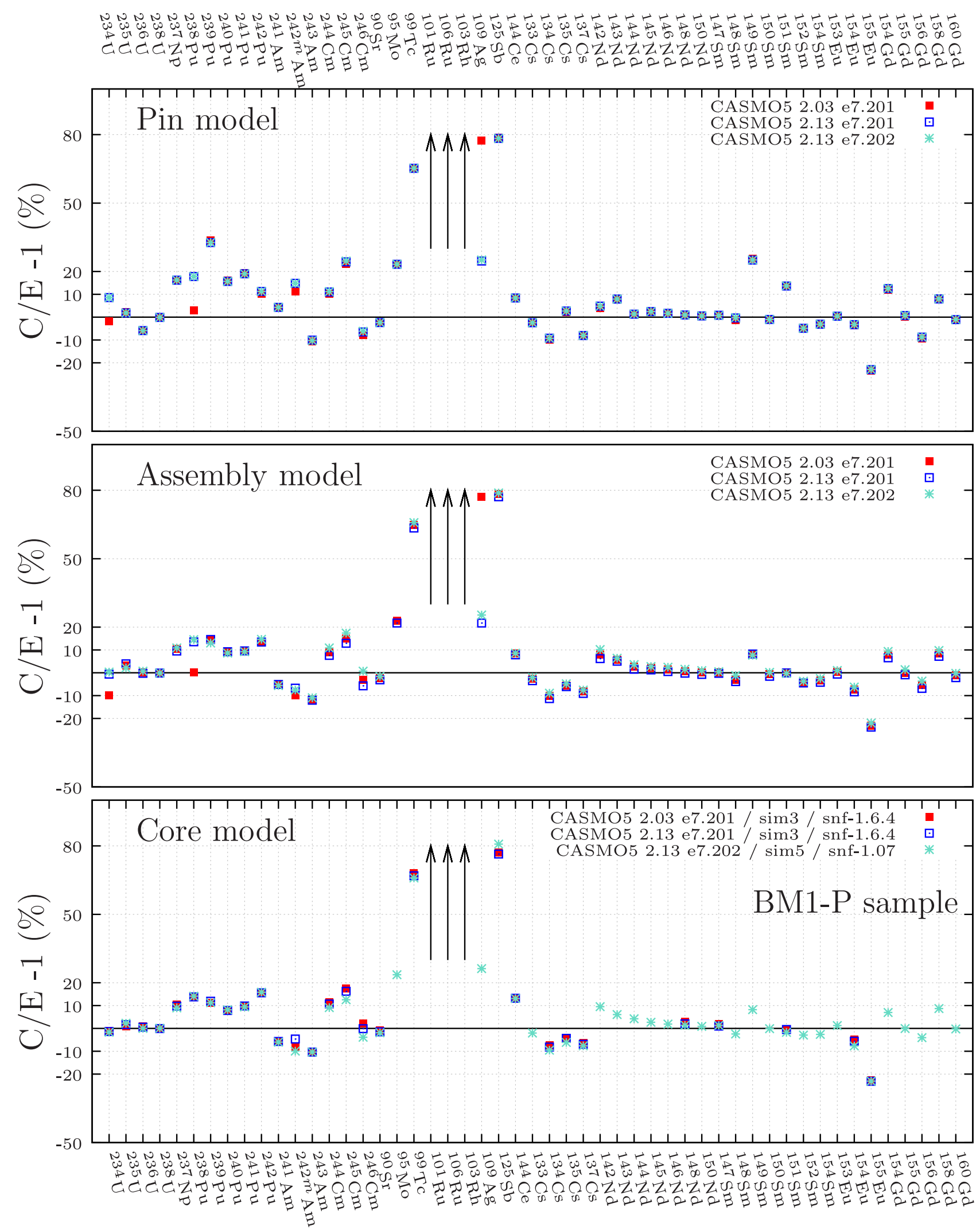

Fig. 4. Comparisons between calculated and measured values $(\mathrm{C} / \mathrm{E}-1)$ for each measured isotopes from different calculations for the BM1-P measurements (PSI); top and middle: CASMO5 2D calculations only, bottom: 3D-1 case. Vertical arrows indicate out-of-scale values. 
Table 1. Comparison of calculated sample burnup values, following different methods. Values are provided in $\mathrm{MWd} / \mathrm{kgHM}$.

\begin{tabular}{llll}
\hline & BM1-P & BM1-S & BM3 \\
\hline 2D pin & 46.8 & 45.1 & - \\
2D assembly, no adjustment & 47.9 & 47.9 & 47.2 \\
2D assembly, adjustment to BM1-P/-S & 46.7 & 45.6 & $45.9 / 44.8$ \\
2D assembly, adjustment to BM3 & 48.0 & 48.0 & 47.2 \\
3D core version (3D-1) & 47.6 & 47.6 & 47.9 \\
3D core version (3D-2) & 47.7 & 47.7 & 48.3 \\
3D core version (3D-3) & 47.4 & 47.4 & 46.7 \\
Average $\pm 1 \sigma$ & $47.4 \pm 1 \%$ & $47.0 \pm 2.5 \%$ & $46.8 \pm 2.6 \%$ \\
$\mathrm{E}\left({ }^{148} \mathrm{Nd}\right)(\mathrm{mg} / \mathrm{gU})$ & $0.562 \pm 0.028$ & $0.548 \pm 0.002$ & 0.575 \\
\hline
\end{tabular}

Table 2. Comparison of average C/E-1 (in \%) between different types of calculations for BM1-P, BM1-S and BM3. The uncertainties correspond to the standard deviation, or $1 \sigma$. "AC" designates actinides and "FP" fission products. The calculations with SNF 1.07 are performed with the e7.202 library.

\begin{tabular}{lllllll}
\hline Code & AC & FP & AC + FP & AC & FP & AC + FP \\
\hline CASMO5 2.03 (pin) & $+7 \pm 12$ & $+22 \pm 54$ & $+18 \pm 46$ & $-0 \pm 24$ & $+16 \pm 35$ & $+10 \pm 32$ \\
CASMO5 2.03 (assembly) & $+2 \pm 9$ & $+21 \pm 55$ & $+15 \pm 46$ & $-0 \pm 21$ & $+15 \pm 34$ & $+8 \pm 31$ \\
SNF 1.07 (full core) & $+4 \pm 9$ & $+21 \pm 55$ & $+15 \pm 46$ & $-1 \pm 11$ & $+17 \pm 34$ & $+10 \pm 29$ \\
\hline \multirow{5}{*}{ Code } & AC & FP & AC + FP & & & \\
\hline CASMO5 2.03 (assembly) & $-5 \pm 6$ & $-1 \pm 3$ & $-3 \pm 6$ & & \\
SNF 1.07 (full core) & $-3 \pm 5$ & $-3 \pm 5$ & $-3 \pm 5$ & & \\
\hline
\end{tabular}

that the impact of the geometry seems to be more pronounced for actinides. Larger deviations from $C / E=1$ can be observed from the pin model, especially for the $\mathrm{Pu}$ and $\mathrm{Cm}$ isotopes (as $\mathrm{Cm}$ isotopes are built-up from neutron capture on $\mathrm{Pu}$ isotopes). Similarly, ratios for fission products are also improved from a simple pin model to a more complicated one, but in a more moderated manner. The improvement from a $2 \mathrm{D}$ assembly model to a $3 \mathrm{D}$ full core is less pronounced, although the trend indicates an improvement for the actinides of the BM1-S sample. This trend of improvement for the isotopic $\mathrm{C} / \mathrm{E}$ ratios was less visible for the GU1 sample, but the considered geometry was only a 2D assembly and a 3D full core. One should also note that the $2 \mathrm{D}$ calculations are adjusted to the ${ }^{148} \mathrm{Nd}$ contents, whereas the 3D calculations are not. Regarding the comparison of measured concentrations from BM1$\mathrm{S}$ and BM1-P, one can see that for the $\mathrm{Pu}$ isotopes, 2D assembly calculations differ from measurements for both samples, whereas an improvement is observed with the full core model. Consequently, at least in the case of the $\mathrm{Pu}$ isotopes, a 3D full core model provides a better agreement.

For isotopes with $\mathrm{C} / \mathrm{E}$ ratios very different than $1(\mathrm{Ru}$ and $\mathrm{Rh}$ isotopes), the changes in models, geometries or code versions do not strongly modified the results (similar results were obtained in Ref. [27]). A study of the BM1 sample (both BM1-S and BM1-P) is presented in reference [27], based on CASMO5 (version 2.10.00) and CASMO-4E. Different libraries and geometry are used, and a detailed comparison with the presented results is not performed here, but one can observe that concerning actinides, similar trends were observed, although less strong in the present calculations (for the main fissioning actinides ${ }^{239,241} \mathrm{Pu}$ and ${ }^{235} \mathrm{U}$, as well as for the $\mathrm{Cm}$ isotopes).

\subsection{Uncertainties due to nuclear data}

As explained, the uncertainties due to nuclear data were calculated using covariance files from the main three libraries, for the pin model, as well as for the $2 \mathrm{D}$ assembly and 3D full core models. Only the case of the BM1-P sample is considered. Tabulated results at the time of measurement are presented in Tables B.6, B.7 and B.8.

The first remark is that different covariance files from different libraries will lead to different uncertainties for nuclide concentrations. Uncertainties can vary by a factor more than $2\left({ }^{234,236} \mathrm{U},{ }^{237} \mathrm{~Np},{ }^{238} \mathrm{Pu},{ }^{101} \mathrm{Ru},{ }^{109} \mathrm{Ag}\right.$, ${ }^{133,134} \mathrm{Cs},{ }^{142} \mathrm{Nd},{ }^{151} \mathrm{Sm},{ }^{155} \mathrm{Eu}$ and ${ }^{155-160} \mathrm{Gd}$ ), due to differences in fission yield uncertainties, or sometimes simple lack of covariance data for cross sections. Compared to the GU3 sample $\left(\mathrm{UO}_{2}\right.$ sample, with a burnup close to the one of BM1), uncertainties differ, but are still comparable. For instance, for ${ }^{244} \mathrm{Cm}$ which is an important neutron emitter for cooling time lower than 30 years, uncertainties for the MOX sample are somewhat smaller (4-7\%) compared to the $\mathrm{UO}_{2}$ samples $(8-10 \%)$. Such numbers cannot easily be compared, as sample burnup values are different and initial fissile contents are different. As for another important isotope, ${ }^{137} \mathrm{Cs}$, its calculated uncertainties are different (but close to each other) from a library to another one, 
and also similar to the $\mathrm{UO}_{2}$ cases. Finally, in the case of ${ }^{134} \mathrm{Cs}$, an isotope being important for the decay heat uncertainty below 20 years of cooling time, values strongly vary from a library to the other, as in the $\mathrm{UO}_{2}$ cases (the lower uncertainty from the JEFF-3.3 library comes from a lower fission yield uncertainty).

The second important remark concerns the calculated uncertainties for different models (2D pin, 2D assembly, and 3D full core). Values can be found in Tables B.7 and B.8 for the covariance files from the ENDF/B-VIII.0 library. In the case of the full core, because the SNF version from the $3 \mathrm{D}-1$ code combination does not provide concentrations for all isotopes, only uncertainties for a limited number of fission products are indicated. It was already mentioned that nominal values are different between these calculations, and as presented in this table, some uncertainties are also different. Uncertainties based on the $2 \mathrm{D}$ pin model seem to be equal or larger than from the other calculations, indicating a possible overestimation of uncertainties.

A comparison between the $2 \mathrm{D}$ assembly and the $3 \mathrm{D}$ full core models shows that globally, uncertainties are relatively close, but there is a tendency to obtain slightly higher uncertainties for fission products in the $3 \mathrm{D}$ case. One of the conclusions of this study is that if $\mathrm{C} / \mathrm{E}$ values depend on the considered models, it is alike for uncertainties: their values depend on the assumptions, modelling and simulation tools.

\subsection{Partial effects of nuclear data}

Partial effects of nuclear data were already studied for GU1 and GU3. In a similar way, some nuclear data are varied without others and results are presented in this section. All partial variations are based on the ENDF/BVIII.0 library. In the case of the GU3 sample, the main contributors to the fission rates were ${ }^{235} \mathrm{U},{ }^{239,241} \mathrm{Pu}$ and ${ }^{238} \mathrm{U}$, with $50,35,7$ and $8 \%$ of the total integrated fission events, respectively, as indicated in the $2 \mathrm{D}$ assembly calculations. Values were similar for the GU1 sample (GU1 had a higher burnup than GU3). For BM1, such contribution is different, being a MOX sample, and the fission rates are 2, 66, 23 and $9 \%$ of the total integrated fission events, respectively. One can see the smaller importance of ${ }^{235} \mathrm{U}$ to the benefits of the fissile $\mathrm{Pu}$ isotopes. Such shift in the importance is also reflected in the individual contributions to the uncertainties. Figure 5 shows the importance of FY and XS for the measured isotopes, as well as the importance of the main contributors to the uncertainties.

Regarding the global contributions of FY and XS (top part of Fig. 5), similar distributions were obtained for GU1 and GU3 (using the same covariance information). As expected, cross sections are mainly influencing the actinide concentrations, and fission yields have a negligible effect. In the case of the fission products, fission yields start to be important (depending on the uncertainties of the mass chain), but cross sections (mainly capture cross sections) are also dominant quantities for a number of isotopes (some of the $\mathrm{Nd}, \mathrm{Sm}$ and Eu isotopes).
The change for BM1 compared to the other $\mathrm{UO}_{2}$ isotopes is the contributions from the fission yields (middle part of Fig. 5). The two $\mathrm{Pu}$ fissile isotopes are almost the only contributors to the uncertainties due to fission yields, with the predominance of ${ }^{239} \mathrm{Pu}$. This is not surprising, given the mentioned integrated fission rates.

Finally, the contributions from the main cross sections are presented in the bottom part of Figure 5. For fission products, various capture cross sections can modify specific concentrations (both capture cross sections leading an isotope, as well as the one removing it). For actinides, the number of important cross sections is smaller, although it can be both capture and fission cross sections, as indicated in the figure. An interesting example is ${ }^{239} \mathrm{Pu}$ : for the $\mathrm{UO}_{2}$ samples, the main contributor to the ${ }^{239} \mathrm{Pu}$ uncertainty was ${ }^{238} \mathrm{U}(\mathrm{n}, \gamma)$, given that there was no $\mathrm{Pu}$ content in the fresh sample. For BM1, the main contributor is the ${ }^{239} \mathrm{Pu}(\mathrm{n}, \gamma)$ reaction, as relatively large amounts of ${ }^{239} \mathrm{Pu}$ are already present in the sample at the beginning of irradiation. Therefore, both cross sections are important for the knowledge of $\mathrm{Pu}$ content in spent fuel. If the ${ }^{238} \mathrm{U}(\mathrm{n}, \gamma)$ is relatively well known from a nuclear data evaluation point of view, the ${ }^{239} \mathrm{Pu}(\mathrm{n}, \gamma)$ is not considered known to the same level, mainly due to the difficulties linked to the competing fission channel. A last remark can be made for the ${ }^{244} \mathrm{Cm}$ isotope: for the $\mathrm{UO}_{2}$ and MOX samples, the ${ }^{242} \mathrm{Pu}(\mathrm{n}, \gamma)$ is the main source of uncertainty to the ${ }^{244} \mathrm{Cm}$ concentration.

As observed in Table B.8, in the case of fission products having small uncertainties in the 2D assembly modelling (uncertainties due to XS for ${ }^{90} \mathrm{Sr},{ }^{99} \mathrm{Tc},{ }^{106} \mathrm{Ru},{ }^{125} \mathrm{Sb}$, ${ }^{144} \mathrm{Ce},{ }^{135,137} \mathrm{Cs}$ and ${ }^{148} \mathrm{Nd}$ ), large differences can be observed, and all uncertainties are not smaller than $1 \%$ using the 3D full core model. In the particular case of ${ }^{148} \mathrm{Nd}$, as the total uncertainties are mainly driven by XS uncertainties in the 3D case, a factor 2 can be observed, from $0.5 \%(2 \mathrm{D})$ to $1.1 \%(3 \mathrm{D})$. Given the importance of this isotope for the burnup calculation, such difference is not negligible. In the case of the $3 \mathrm{D}$ calculations, the decomposition of the $1.1 \%$, obtained from additional calculations where only the XS for ${ }^{235,238} \mathrm{U}$ and ${ }^{239,241} \mathrm{Pu}$ are separately varied, indicates that the main difference comes from the contribution of ${ }^{239} \mathrm{Pu}$ : less than $0.1 \%$ in $2 \mathrm{D}$, and close to $1 \%$ in $3 \mathrm{D}$. This reflects the fact that the variations of ${ }^{239} \mathrm{Pu}$ have more effect in the full core model compared to the single assembly model. A possible explanation is that in the single assembly model, reflective boundary conditions are used: only one type of assembly is effectively assumed: variations of the main ${ }^{239} \mathrm{Pu}$ cross section, namely fission, are simply compensated by a modification of the neutron flux level, as the assembly power is fixed (given in the input definition). Consequently, a decrease of a ${ }^{239} \mathrm{Pu}$ cross section is compensated by an increase in neutron flux. The effect of a change of a ${ }^{239} \mathrm{Pu}$ cross section on fission products will therefore be modest. In the full core model, there is on the contrary a mixture of $\mathrm{MOX}$ and $\mathrm{UO}_{2}$ assemblies: variations of the ${ }^{239} \mathrm{Pu}$ (fission) cross section will simply modify the released power of MOX assemblies, compensated at the core level by an increase of the neutron flux, as the core power is fixed (and not the assembly power). The changes in power from the 

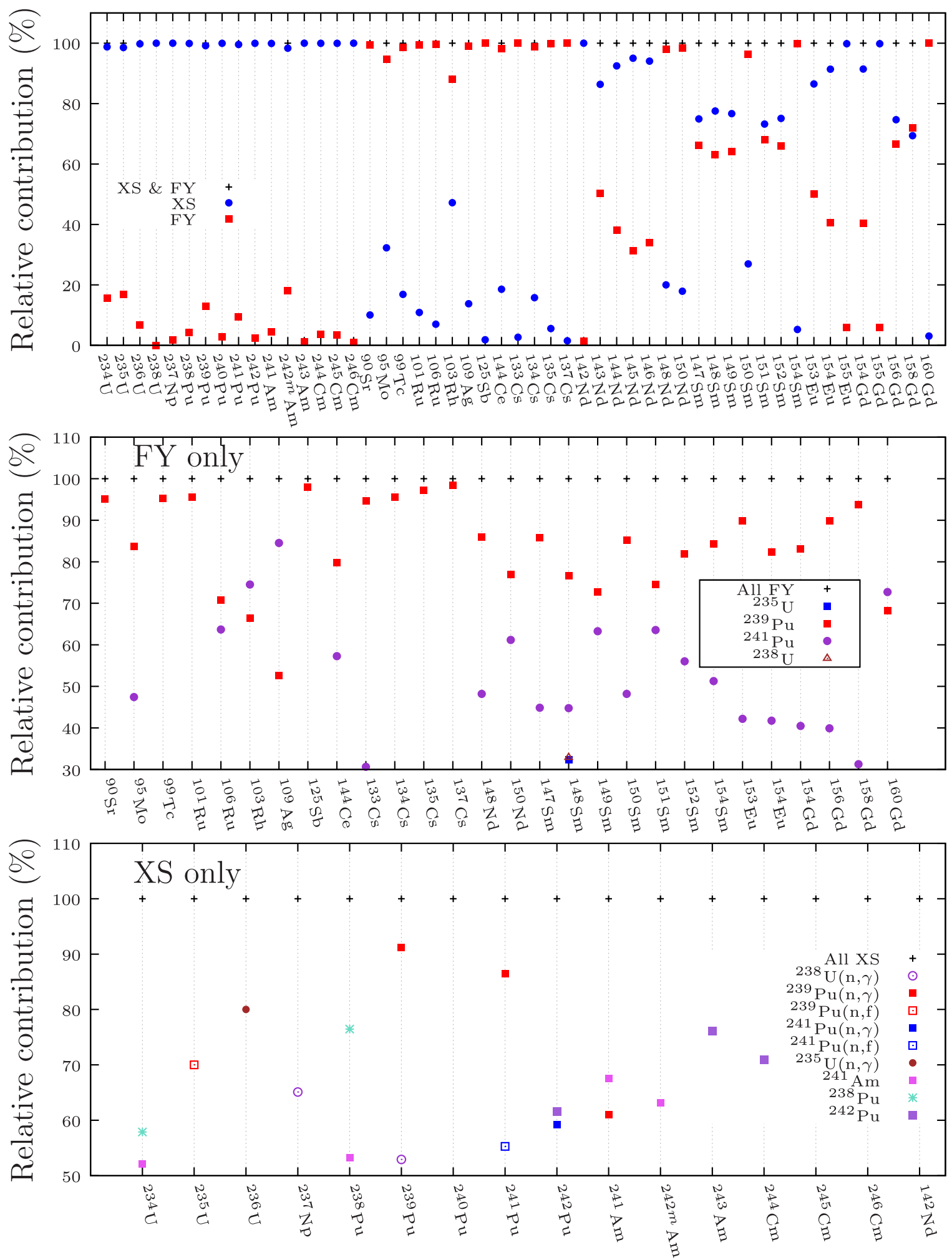

Fig. 5. Relative contributions of the cross sections (called XS) and fission yields (called FY) to the total uncertainties. For XS and FY, the main contributors are also indicated.

$\mathrm{UO}_{2}$ assemblies will be inversed of the one from the MOX, compensating such changes in the ${ }^{239} \mathrm{Pu}$ cross section. This hypothesis is supported by the changes in $\mathrm{UO}_{2}$ and
MOX burnup assemblies: they are strongly anti-correlated with variations of ${ }^{239} \mathrm{Pu}$ cross sections (with a correlation factor close to -1 ), indicating that lower power from 
MOX assemblies is compensated by a higher one from $\mathrm{UO}_{2}$ assemblies (and vice versa). The same effect appears due to variations of ${ }^{239} \mathrm{Pu}$ nubar.

This underlines that the calculated uncertainties depend on the type of simulation performed, including assumptions such as boundaries and normalizations.

\subsection{Uncertainties from operating conditions and manufacturing tolerances}

The uncertainties from the operating conditions and manufacturing tolerances are presented in Tables B.9 and B.10. As the same variations were applied for the GU1 and GU3 samples, values for these samples are also indicated.

The first remark is that the uncertainties due to nuclear data are the main ones (even when considering the lower values from the differences in library covariance files). This was also the case for the $\mathrm{UO}_{2}$ samples. The impact of the moderator temperature and pitch can be of importance, but are still small compared to the nuclear data impact. An exception is ${ }^{239} \mathrm{Pu}$, which seems to be sensitive to various parameters (temperature, pitch, rod position). The impact of the moderator temperature (TMO) is therefore of importance for the knowledge of spent fuel, and not only for a specific vertical segment where a sample is located. The radial and axial TMO distributions can locally affect isotopic concentrations, even if the average quantities are better known. This can be of importance when 3D models are needed, for instance for criticality calculations of spent fuel storage [15].

In comparison to the uncertainties for the $\mathrm{UO}_{2}$ samples, local differences can be found; order of magnitudes are conserved between samples, even if differences close to a factor 2 can be observed.

\subsection{Expanded uncertainties}

The expanded uncertainties allow to aggregate together calculated and experimental uncertainties, and the observed biases. It is well described in the guidelines of the National Institute of Standards and Technology, see reference [28], and was applied for the $\mathrm{UO}_{2}$ samples. Two quantities are presented in Table B.11 for the BM1-P measurements: the RSSU (root-sum-of-squares including biases) and $\operatorname{SUMU}$ (asymmetric uncertainty band). For both of them, only the maximum nuclear data uncertainties are used.

Such quantities are dependent on the specific sample under consideration, as biases and experimental uncertainties can strongly vary from one sample to the other. These expanded uncertainties can be more useful when a large number of samples has been analyzed in a similar way, and trends taking into account sample characteristics can be observed. This is of course a substantial amount of work, but it seems necessary in order to assess the confidence in a specific calculation scheme. Such work is expected to happen in the future, for instance as one of the conclusions of the EURAD project.

\section{Decay heat and decay heat uncertainties}

Similar to the study of GU1 and GU3, the decay heat (and its uncertainties) of the assembly containing the BM1 and BM3 samples can be calculated based on the previous CASMO5 model for the BM1-P case. Results are presented in Figures 6 and 7 and in Tables B.12 and B.13. Decay heat values and their uncertainties were calculated from one week after the end of irradiation up to 500000 years, but the tables present numerical quantities from about one month up to 100000 years.

Again, the same method as for the $\mathrm{UO}_{2}$ samples is applied here, as well as the same variations of model parameters. The decay heat values up to 100000 years are calculated with the SNF-lite module and details can be found in references $[5,6]$. As seen in Figure 6, comparing the decay heats from the three MOX and $\mathrm{UO}_{2}$ assemblies, the decay heat values (in Watt per tons) for the MOX assembly are larger than for the $\mathrm{UO}_{2}$, independently of the initial fissile content enrichment, or of their burnup at the end of irradiation. This is due to an increased contribution from heavy actinides $\left({ }^{238} \mathrm{Pu}\right.$, ${ }^{241} \mathrm{Am}$ and ${ }^{244} \mathrm{Cm}$ ).

In addition to the nominal calculations, calculated uncertainties are presented in Figure 7 and in Tables B.12 and B.13. The dark vertical band in Figure 7 indicates the PIE measurement period. Compared to the $\mathrm{UO}_{2}$ samples, uncertainties are lower, especially at the cooling time where ${ }^{134} \mathrm{Cs}$ is the main contributor. The importance of ${ }^{134} \mathrm{Cs}$, reaching the maximum uncertainty at 3 years, is reduced in the case of BM1, as heavy actinides contributes more the decay heat (see Fig. 6 for ${ }^{244} \mathrm{Cm}$ and ${ }^{238} \mathrm{Pu}$ ).

The effect of the manufacturing tolerances and operating conditions are calculated as for the nuclide compositions and are presented in Table B.12. As observed, nuclear data are (once again) the main source of uncertainties, and the only other relevant quantity is the assembly pitch. Variations between libraries are less significant compared to isotopic compositions, certainly due to compensation effects between the isotopic contributions to the decay heat. From this aspect, decay heat is similar to the $\mathrm{k}_{\mathrm{eff}}$ quantity from criticality benchmarks: individual components might be less known than their integral effects.

Similar to the nuclide compositions, expanded uncertainties are also proposed in Table B.13. The same approach was followed for the two $\mathrm{UO}_{2}$ samples. For the decay heat, biases are not known, and instead the isotopic biases are used, with respect to the isotope contributions to the decay heat. For instance, if the concentration bias for ${ }^{244} \mathrm{Cm}$ is $+10 \%$ in the case of the BM1-P measurement, we assume that its contribution to the decay heat will also be overestimated by the same amount, with the simplification that this bias is constant as a function of cooling time. This is certainly an approximation, which might only be removed by actual decay heat measurements. For isotopes contributing to the decay heat but not available from the PIE values (for instance due to a short half-life), their measured daughter isotopes are considered instead. Such approach lead to the values presented in Table B.13, which are however approximations. 


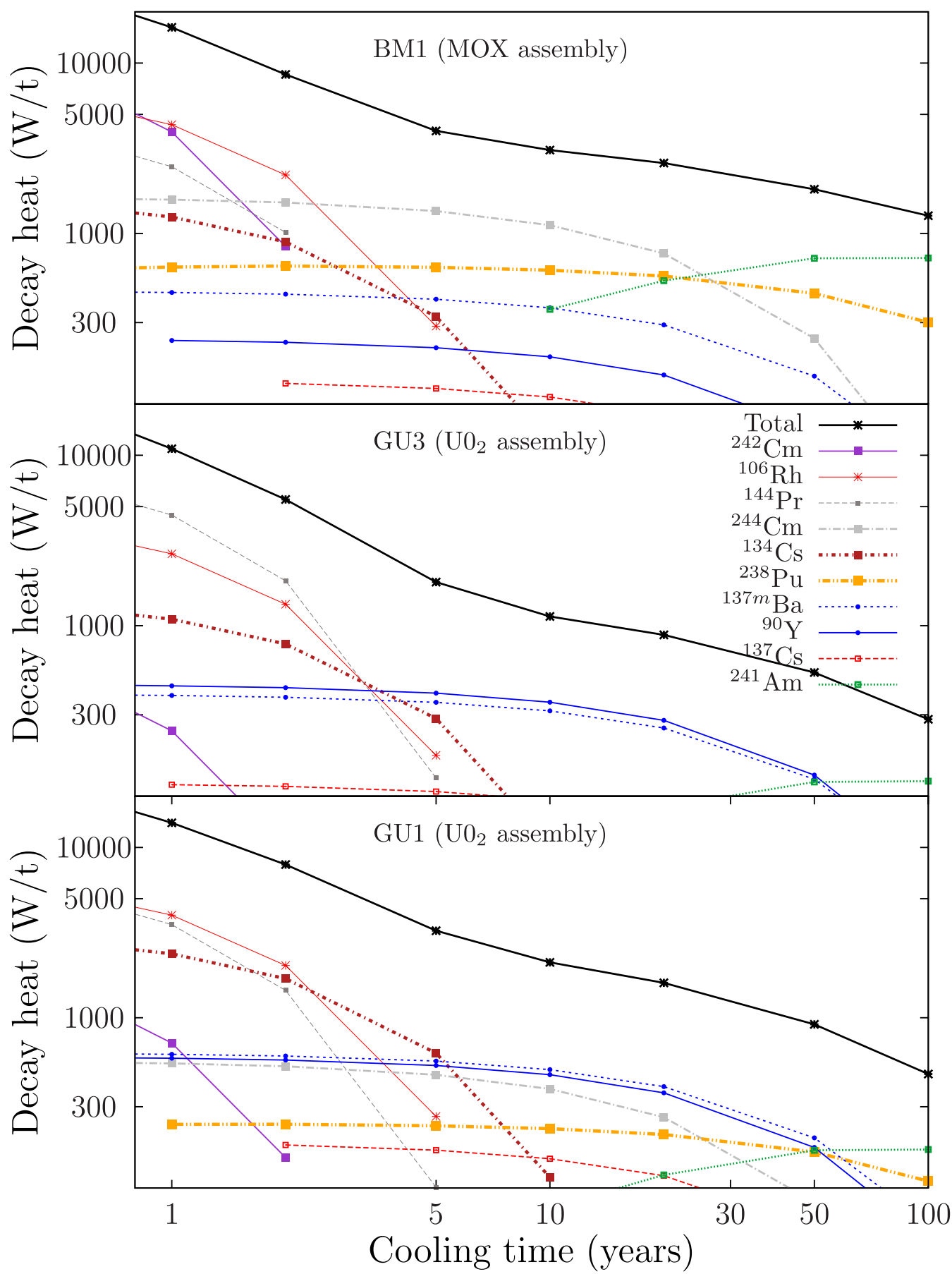

Fig. 6. Total decay heat for the MOX (this work) and two $\mathrm{UO}_{2}$ assemblies $[5,6]$ containing the samples. The main contributors are also shown.

Following this approach, it can be seen that expanded uncertainties can be relatively high for short cooling times (less than 10 years), due to strong biases for isotopes such as ${ }^{106} \mathrm{Rh}$. These values might be different for other samples (and therefore assemblies); ironically, if no biases are known, expanded uncertainties can be lower. An alternative is to adopt a specific generic bias, from dedicated studies.

\section{Conclusion}

This work presents the analysis of two MOX samples from the ARIANE program, called BM1 and BM3. A number of measured and calculated nuclide concentrations are compared, under different modelling assumptions: 2D pin cell, 2D assembly and 3D full core. The simulation tools are CASMO5 in the case of the 2D simulations, and CASMO5 


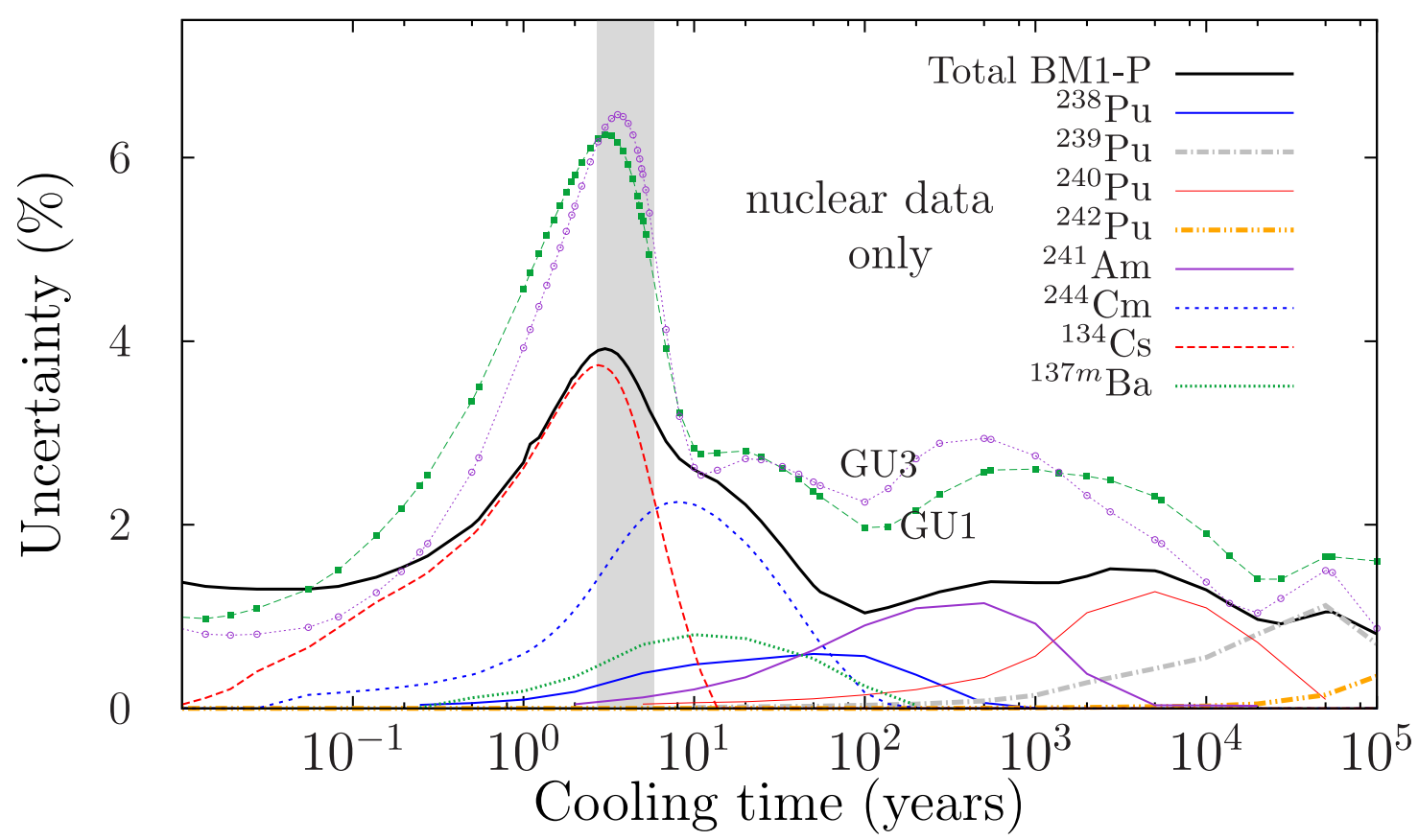

Fig. 7. Calculated decay heat uncertainties for the assembly containing the BM1 sample, due to nuclear data (with the ENDF/BVIII.0 library). The ten most important contributors for the uncertainties are also presented. The dotted lines indicate the decay heat uncertainties from the GU1 and GU3 assemblies.

coupled with SIMULATE and SNF for the 3D calculations. The decay heat for the assembly containing these samples was also provided. Additionally, uncertainties from nuclear data, operating conditions and manufacturing tolerances were calculated for both nuclide inventory and decay heat. Finally, both biases and uncertainties are combined into expanded uncertainties.

It was found that if nuclide concentrations vary with the modelling assumptions, uncertainties also depend on the considered model. The 3D simulation allows to avoid normalizing the irradiation history to match the measured ${ }^{148} \mathrm{Nd}$ measured concentration (as for the 2D simulations), and also provides better $\mathrm{C} / \mathrm{E}$ values. It was confirmed that nuclear data are the main sources of uncertainties for both nuclide inventory and decay heat, similarly to the case of $\mathrm{UO}_{2}$ samples.

As a final word, this work confirms that calculated values (isotopic concentrations, uncertainties, decay heat) depend on the calculation scheme; if this is not a new finding (except perhaps for uncertainties), it confirms the fact that these quantities shall not be taken out of their context.

\section{Funding}

This work was partly supported by swissnuclear, the association of the Swiss nuclear power station operators, with the COLOSS project. It was also partly funded by the European Union's Horizon 2020 Research and Innovation Programme under grant agreement No 847593 (EURAD, Work Package 8 on "Spent Fuel Characterisation and evolution until disposal").

\section{Author contribution statement}

All the co-authors contributed equally to this work (modelling, simulations, analysis and writing).

\section{References}

1. European Joint Programme on Radioactive Waste Management, EU H2020-Euratom-1.2 program, Grant agreement ID: 847593, https://cordis.europa.eu/project/id/847593

2. Coordinated Research Project (CRP) on Spent Fuel Characterization (T13018). https://www.iaea.org/newscenter/ news /new-crp-spent-fuel-characterization-t13018

3. ARIANE International Programme Final Report, Belgonucléaire, AR2000/15 BN Ref. 0000253/221, Revision B, December 2000

4. F. Michel-Sendis et al., SFCOMPO-2.0: An OECD NEA database of spent nuclear fuel isotopic assays, reactor design specifications, and operating data, Ann. Nucl. Energy 110, 779 (2017)

5. D. Rochman, A. Vasiliev, H. Ferroukhi, M. Hursin, Analysis for the ARIANE GU1 sample: nuclide inventory and decay heat, Ann. Nucl. Energy 160, 108359 (2021)

6. D. Rochman, A. Vasiliev, H. Ferroukhi, M. Hursin, R. Ichou, J. Taforeau, T. Simeonov, Analysis for the ARIANE GU3 sample: nuclide inventory and decay heat, EPJ Nuclear Sci. Technol. 7, 14 (2021)

7. J. Rhodes, K. Smith, D. Lee, CASMO-5 development and applications, in Proceedings of the PHYSOR-2006 conference, ANS Topical Meeting on Reactor Physics, Vancouver, BC, Canada, September 10-14, Vancouver, BC, Canada, September 10-14, 2006 (2006), p. B144 
8. A.S. DiGiovine, J.D. Rhodes III, K.S. Smith, D.M. Ver Planck, J.A. Umbarger, SIMULATE-3 Users Manual, Studsvik/SOA-95/15, Studsvik (1995)

9. T. Simeonov, C. Wemple, Update and evaluation of decay data for spent nuclear fuel analyses, Proceedings of the International Conference on Nuclear Data for Science and Technology, ND2016, Bruges, Belgium, September 11-16, 2016, EPJ Web Conf. 146, 09011 (2017)

10. D. Rochman, A. Vasiliev, H. Ferroukhi, M. Seidl, J. Basualdo, Improvement of PIE analysis with a full core simulation: The U1 case, Ann. Nucl. Energy 148, 107706 (2020)

11. O. Leray, H. Ferroukhi, M. Hursin, A. Vasiliev, D. Rochman, Methodology for core analyses with nuclear data uncertainty quantification and application to Swiss PWR operated cycles, Ann. Nucl. Energy 110, 547 (2017)

12. H. Ferroukhi, K. Hofer, J.M. Hollard, A. Vasiliev, M.A. Zimmermann, Core modelling and analysis of the Swiss Nuclear Power Plants for qualified R\&D applications, in the Proceedings of the Int. Conf. on the Physics of Reactors, PHYSOR'08, Interlaken, Switzerland (2008)

13. D. Rochman, A. Dokhane, A. Vasiliev, H. Ferroukhi, M. Hursin, Nuclear data uncertainties for core parameters based on Swiss BWR operated cycles, Ann. Nucl. Energy 148, 107727 (2020)

14. D. Rochman, A. Vasiliev, A. Dokhane, H. Ferroukhi, Uncertainties for Swiss LWR spent nuclear fuels due to nuclear data, EPJ Nuclear Sci. Technol. 4, 6 (2018)

15. D. Rochman, A. Vasiliev, H. Ferroukhi, M. Pecchia, Consistent criticality and radiation studies of Swiss spent nuclear fuel: the $\mathrm{CS}_{2} \mathrm{M}$ approach, J. Hazard. Mater. 357, 384 (2018)

16. D. Rochman, A. Vasiliev, H. Ferroukhi, M. Pecchia, Optimization of Swiss used nuclear fuel canister for final repository: homogeneous vs. mixed loading, Ann. Nucl. Energy 148, 107756 (2020)

17. D. Rochman, A. Dokhane, A. Vasiliev, H. Ferroukhi, M. Hursin, Nuclear data uncertainties for Swiss BWR spent nuclear fuel characteristics, Eur. Phys. J. Plus 135, 233 (2020)

18. R. Macian, M.A. Zimmermann, R. Chawla, Assessment of CASMO-4 predictions of the isotopic inventory of high burnup MOX fuel, in Proceedings of PHYSOR 2004 Conference, Chicago, USA, April 24-29 (2004)
19. D.A. Brown et al., ENDF/B-VIII.0: The 8th Major Release of the Nuclear Reaction Data Library with CIELO-project Cross Sections, New Standards and Thermal Scattering Data, Nucl. Data Sheets 148, 1 (2018)

20. A.J.M. Plompen et al., The joint evaluated fission and fusion nuclear data library, JEFF-3.3, Eur. Phys. J. A 56, 181 (2020)

21. K. Shibata et al., JENDL-4.0: a new library for nuclear science and engineering, J. Nucl. Sci. Technol. 48, 1 (2011)

22. M. Hursin, S. Pelloni, A. Vasiliev, H. Ferroukhi, Treatment of the implicit effect in Shark-X, Ann. Nucl. Eng. 138, 107178 (2020)

23. O. Leray, D. Rochman, P. Grimm, H. Ferroukhi, A. Vasiliev, M. Hursin, G. Perret, A. Pautz, Nuclear data uncertainty propagation on spent fuel nuclide compositions, Ann. Nucl. Energy 94, 603 (2016)

24. O. Leray, P. Grimm, M. Hursin, Ferroukhi, A. Pautz, Uncertainty quantification of spent fuel nuclide compositions due to cross-sections, decay constants and fission yields, in PHYSOR 2014 - The Role of Reactor Physics Toward a Sustainable Future, The Westin Miyako, Kyoto, Japan, September 28 - October 3, 2014, on CD-ROM (2014)

25. D. Rochman, O. Leray, M. Hursin, H. Ferroukhi, A. Vasiliev, A. Aures, F. Bostelmann, W. Zwermann, O. Cabellos, C.J. Diez, J. Dyrda, N. Garcia-Herranz, E. Castro, S. van der Marck, H. Sjöstrand, A. Hernandez, M. Fleming, J.-Ch. Sublet, L. Fiorito, Nuclear data uncertainties for typical LWR fuel assemblies and a simple reactor core, Nucl. Data Sheets 139, 1 (2017)

26. D. Rochman, Quantification of Uncertainties and Biases in CASM0-5 calculations of ${ }^{244} \mathrm{Cm}$ nuclide compositions for the Ul, U2, U7, BMl and BM5 samples, PSI report, TM-4116-10, 2016

27. E. Georgieva, J. Hykes, R. Ferrer, J. Rhodes, CASMO5 isotopic comparison to the ARIANE mixed-oxyde pressurized water reactor spent fuel measurements, in PHYSOR 2018: Reactor Physics paving the way towards more efficient systems Cancun, Mexico, April 22-26, 2018 (2018)

28. S.D. Phillips, K.R. Eberhardt, B. Parry, Guidelines for expressing the uncertainty of measurement results containing uncorrected bias, J. Res. Natl. Inst. Stand. Technol. 102, 577 (1997)

Cite this article as: Dimitri Rochman, Alexander Vasiliev, Hakim Ferroukhi, Mathieu Hursin, Analysis for the ARIANE BM1 and BM3 samples: nuclide inventory and decay heat, EPJ Nuclear Sci. Technol. 7, 18 (2021) 


\section{Appendix A: C/E plots for BM1-S and BM3}

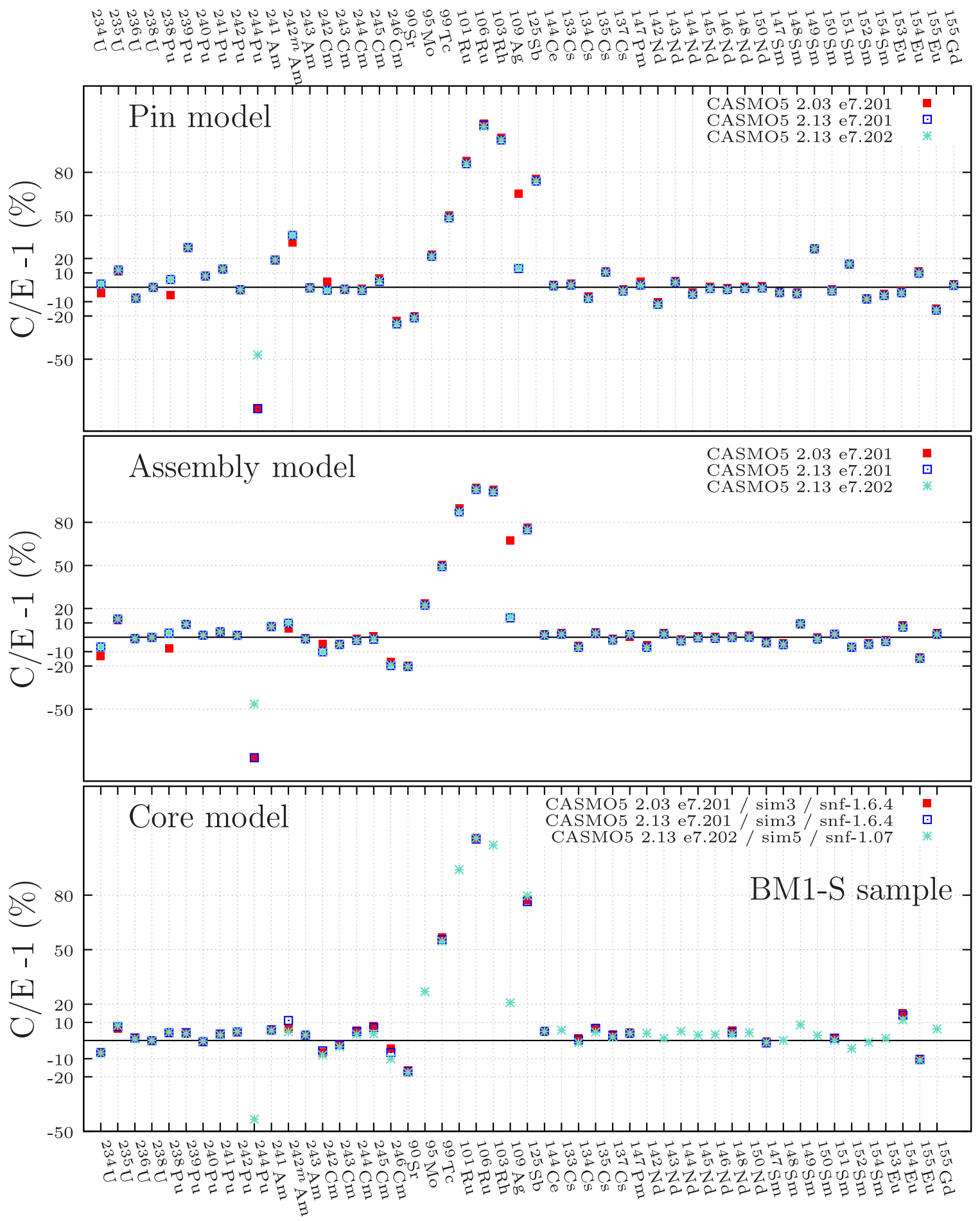

Fig. A.1. Comparisons between calculated and measured values from for each measured isotopes from different calculations for the BM1-S measurements (SCK-MOL); top: CASMO5 calculation only, bottom: 3D-1 case. 


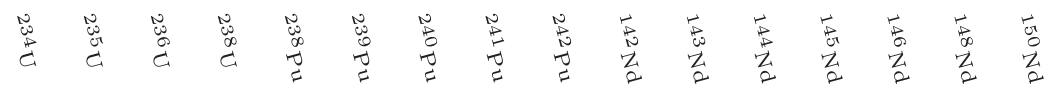

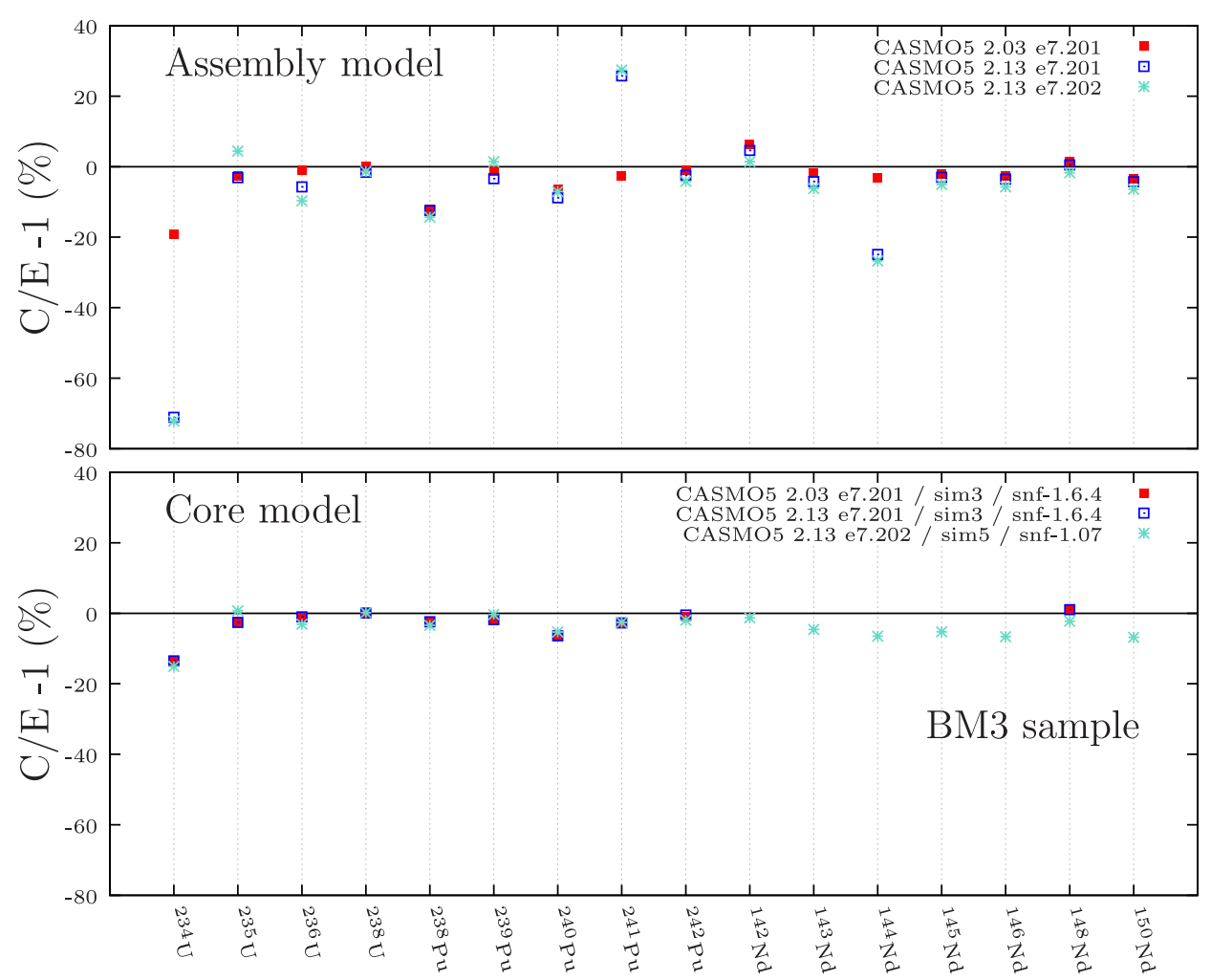

Fig. A.2. Comparisons between calculated and measured values $(\mathrm{C} / \mathrm{E}-1)$ for each measured isotopes from different calculations for the BM3 sample (PSI measurements); top: CASMO5 calculation only, bottom: 3D-1 case. 


\section{Appendix B: Tabulated isotopic compositions and uncertainties}

Table B.1. Measured concentrations for the BM1-P (from PSI) and BM1-S (from SCK-CEN) samples, with their experimental uncertainties for actinides in $\%(1 \sigma)$. Differences are expressed relatively to the PSI values.

\begin{tabular}{|c|c|c|c|c|c|c|c|c|c|c|c|}
\hline & \multicolumn{2}{|c|}{ BM1-P } & \multicolumn{2}{|c|}{ BM1-S } & \multirow{2}{*}{$\begin{array}{l}\text { Diff. } \\
(\%)\end{array}$} & & \multicolumn{2}{|c|}{ BM1-P } & \multicolumn{2}{|c|}{ BM1-S } & \multirow{2}{*}{$\begin{array}{l}\text { Diff. } \\
(\%)\end{array}$} \\
\hline & $\mathrm{mg} / \mathrm{gU}$ & $\pm(\%)$ & $\mathrm{mg} / \mathrm{gU}$ & $\pm(\%)$ & & & $\mathrm{mg} / \mathrm{gU}$ & $\pm(\%)$ & $\mathrm{mg} / \mathrm{gU}$ & $\pm(\%)$ & \\
\hline${ }^{234} \mathrm{U}$ & $9.34 \mathrm{E}-2$ & 13.3 & $7.94 \mathrm{E}-2$ & 5.0 & +15 & ${ }^{235} \mathrm{U}$ & 1.08 & 4.2 & 1.02 & 1.0 & +5.5 \\
\hline${ }^{236} \mathrm{U}$ & 0.321 & 3.6 & 0.316 & 2.5 & +1.5 & ${ }^{238} \mathrm{U}$ & 999 & 2.6 & 999 & 0.2 & +0.0 \\
\hline${ }^{237} \mathrm{~Np}$ & 0.187 & 6.0 & - & - & - & ${ }^{238} \mathrm{Pu}$ & 1.24 & 1.9 & 1.37 & 1.5 & -10 \\
\hline${ }^{239} \mathrm{Pu}$ & 13.7 & 1.3 & 14.7 & 0.3 & -7.3 & ${ }^{240} \mathrm{Pu}$ & 13.5 & 1.2 & 14.6 & 0.3 & -8.1 \\
\hline${ }^{241} \mathrm{Pu}$ & 5.38 & 1.2 & 6.17 & 0.3 & -15 & ${ }^{242} \mathrm{Pu}$ & 4.35 & 12 & 4.80 & 0.3 & -10 \\
\hline${ }^{244} \mathrm{Pu}$ & - & - & $8.47 \mathrm{E}-4$ & 25 & - & ${ }^{241} \mathrm{Am}$ & 2.99 & 10 & 1.93 & 1.8 & +35 \\
\hline${ }^{242 m} \mathrm{Am}$ & $2.01 \mathrm{E}-2$ & 10 & $1.75 \mathrm{E}-2$ & 5.3 & +13 & ${ }^{243} \mathrm{Am}$ & 1.40 & 10 & 1.22 & 1.8 & +13 \\
\hline${ }^{242} \mathrm{Cm}$ & - & - & $3.73 \mathrm{E}-4$ & 1.8 & - & ${ }^{243} \mathrm{Cm}$ & . & . & $9.79 \mathrm{E}-3$ & 3.2 & - \\
\hline${ }^{244} \mathrm{Cm}$ & 0.570 & 1.3 & 0.662 & 0.9 & -16 & ${ }^{245} \mathrm{Cm}$ & $7.33 \mathrm{E}-2$ & 1.5 & $7.96 \mathrm{E}-2$ & 2.7 & -8.6 \\
\hline${ }^{246} \mathrm{Cm}$ & $8.11 \mathrm{E}-3$ & 1.8 & $8.68 \mathrm{E}-3$ & 10 & -7.0 & & & & & & \\
\hline${ }^{90} \mathrm{Sr}$ & 0.350 & 5 & 0.440 & 7.5 & -26 & ${ }^{95} \mathrm{Mo}$ & 0.753 & 1.9 & 0.733 & 6.7 & +2.6 \\
\hline${ }^{99} \mathrm{Tc}$ & 0.715 & 1.4 & 0.763 & 14 & -6.7 & ${ }^{101} \mathrm{Ru}$ & 0.600 & 1.8 & 0.657 & 9.2 & -9.5 \\
\hline${ }^{106} \mathrm{Ru}$ & $1.26 \mathrm{E}-3$ & 5.5 & $1.19 \mathrm{E}-2$ & 1.7 & +5.5 & ${ }^{103} \mathrm{Rh}$ & 0.408 & 1.5 & 0.549 & 3.9 & -34 \\
\hline${ }^{109} \mathrm{Ag}$ & 0.106 & 1.0 & 0.110 & 8.3 & -3.7 & ${ }^{125} \mathrm{Sb}$ & $1.62 \mathrm{E}-3$ & 2.2 & $3.11 \mathrm{E}-3$ & 3.0 & -92 \\
\hline${ }^{144} \mathrm{Ce}$ & $9.36 \mathrm{E}-4$ & 5.5 & $9.91 \mathrm{E}-3$ & 4.5 & -5.9 & ${ }^{133} \mathrm{Cs}$ & 1.77 & 2.1 & 1.64 & 1.0 & -7.3 \\
\hline${ }^{134} \mathrm{Cs}$ & $2.36 \mathrm{E}-2$ & 2.3 & $4.62 \mathrm{E}-2$ & 1.0 & -96 & ${ }^{135} \mathrm{Cs}$ & 1.16 & 2.2 & 1.04 & 1.0 & -10 \\
\hline${ }^{137} \mathrm{Cs}$ & 1.76 & 2.0 & 1.68 & 1.0 & +4.5 & ${ }^{142} \mathrm{Nd}$ & $2.06 \mathrm{E}-2$ & 4.9 & $2.23 \mathrm{E}-2$ & 5.0 & -8.2 \\
\hline${ }^{143} \mathrm{Nd}$ & 1.10 & 4.9 & 1.11 & 0.3 & -0.9 & ${ }^{144} \mathrm{Nd}$ & 1.45 & 4.9 & 1.46 & 0.3 & -0.7 \\
\hline${ }^{145} \mathrm{Nd}$ & 0.872 & 5.0 & 0.867 & 0.3 & +0.6 & ${ }^{146} \mathrm{Nd}$ & 0.929 & 5.0 & 0.915 & 0.3 & +1.5 \\
\hline${ }^{148} \mathrm{Nd}$ & 0.562 & 5.0 & 0.548 & 0.3 & +2.5 & ${ }^{150} \mathrm{Nd}$ & 0.338 & 5.1 & 0.327 & 0.3 & +3.2 \\
\hline${ }^{147} \mathrm{Pm}$ & - & - & $7.93 \mathrm{E}-2$ & 4.2 & - & ${ }^{147} \mathrm{Sm}$ & 0.323 & 2.2 & 0.293 & 0.3 & +9.3 \\
\hline${ }^{148} \mathrm{Sm}$ & 0.240 & 2.0 & 0.234 & 0.3 & +2.6 & ${ }^{149} \mathrm{Sm}$ & $6.25 \mathrm{E}-3$ & 5.5 & $6.23 \mathrm{E}-3$ & 1.1 & +0.3 \\
\hline${ }^{150} \mathrm{Sm}$ & 0.460 & 2.1 & 0.447 & 0.3 & +2.8 & ${ }^{151} \mathrm{Sm}$ & $2.96 \mathrm{E}-2$ & 2.3 & $2.96 \mathrm{E}-2$ & 0.4 & +0.0 \\
\hline${ }^{152} \mathrm{Sm}$ & 0.200 & 2.0 & 0.203 & 0.3 & -1.5 & ${ }^{154} \mathrm{Sm}$ & 0.100 & 2.1 & $9.83 \mathrm{E}-2$ & 0.4 & +1.7 \\
\hline${ }^{151} \mathrm{Eu}$ & $1.98 \mathrm{E}-3$ & 30 & $1.05 \mathrm{E}-3$ & 1.1 & +47 & ${ }^{153} \mathrm{Eu}$ & 0.242 & 1.9 & 0.242 & 0.4 & +0.0 \\
\hline${ }^{154} \mathrm{Eu}$ & $4.58 \mathrm{E}-2$ & 2.1 & $4.56 \mathrm{E}-2$ & 1.5 & +0.4 & ${ }^{155} \mathrm{Eu}$ & $9.73 \mathrm{E}-3$ & 2.3 & $1.17 \mathrm{E}-2$ & 2.3 & -20 \\
\hline${ }^{154} \mathrm{Gd}$ & $3.38 \mathrm{E}-2$ & 1.5 & - & - & - & ${ }^{155} \mathrm{Gd}$ & $1.17 \mathrm{E}-2$ & 1.8 & $8.23 \mathrm{E}-3$ & 2.5 & +30 \\
\hline${ }^{156} \mathrm{Gd}$ & 0.191 & 0.7 & - & - & - & ${ }^{158} \mathrm{Gd}$ & $5.17 \mathrm{E}-2$ & 1.1 & - & - & - \\
\hline${ }^{160} \mathrm{Gd}$ & $4.19 \mathrm{E}-3$ & 3.4 & - & - & - & & & & & & \\
\hline
\end{tabular}

Table B.2. Measured concentrations for the BM3 sample (from PSI), after mass balance adjustment. No experimental uncertainties are reported.

\begin{tabular}{llllllll}
\hline & $\mathrm{mg} / \mathrm{gU}$ & & $\mathrm{mg} / \mathrm{gU}$ & & $\mathrm{mg} / \mathrm{gU}$ & $\mathrm{mg} / \mathrm{gU}$ \\
\hline${ }^{234} \mathrm{U}$ & 0.108 & ${ }^{235} \mathrm{U}$ & 1.11 & ${ }^{236} \mathrm{U}$ & 0.330 & ${ }^{238} \mathrm{U}$ & 998 \\
${ }^{238} \mathrm{Pu}$ & 1.46 & ${ }^{239} \mathrm{Pu}$ & 15.5 & ${ }^{240} \mathrm{Pu}$ & 15.6 & ${ }^{241} \mathrm{Pu}$ & 6.02 \\
${ }^{242} \mathrm{Pu}$ & 5.07 & ${ }^{142} \mathrm{Nd}$ & $2.23 \mathrm{E}-2$ & ${ }^{143} \mathrm{Nd}$ & 1.21 & ${ }^{144} \mathrm{Nd}$ & 1.59 \\
${ }^{145} \mathrm{Nd}$ & 0.934 & ${ }^{146} \mathrm{Nd}$ & 1.00 & ${ }^{148} \mathrm{Nd}$ & 0.575 & ${ }^{150} \mathrm{Nd}$ & 0.361 \\
\hline
\end{tabular}


Table B.3. Nominal C/E-1 values and experimental uncertainties for actinides in \% $(1 \sigma)$ for the BM1-P and BM1-S samples.

\begin{tabular}{|c|c|c|c|c|c|c|c|c|}
\hline & \multicolumn{4}{|c|}{ BM1-P } & \multicolumn{4}{|c|}{ BM1-S } \\
\hline & \multirow{2}{*}{\multicolumn{2}{|c|}{$\begin{array}{l}\text { CASMO5 } \\
2.03\end{array}$}} & \multicolumn{2}{|c|}{$\mathrm{SNF}$} & \multirow{2}{*}{\multicolumn{2}{|c|}{$\begin{array}{l}\text { CASMO5 } \\
2.03\end{array}$}} & \multicolumn{2}{|c|}{ SNF } \\
\hline & & & 1.6 .4 & 1.07 & & & 1.6 .4 & 1.07 \\
\hline & $\mathrm{C} / \mathrm{E}-1(\Delta \mathrm{E})$ & $\mathrm{C} / \mathrm{E}-1$ & $\mathrm{C} / \mathrm{E}-1$ & $\mathrm{C} / \mathrm{E}-1$ & $\mathrm{C} / \mathrm{E}-1(\Delta \mathrm{E})$ & $\mathrm{C} / \mathrm{E}-1$ & $\mathrm{C} / \mathrm{E}-1$ & $\mathrm{C} / \mathrm{E}-1$ \\
\hline & Pin & Assembly & Core & Core & Pin & Assembly & Core & Core \\
\hline${ }^{234} \mathrm{U}$ & $-1.7(13.3)$ & -9.8 & -1.1 & -1.6 & $-4.2(5.0)$ & -13 & -6.4 & -6.9 \\
\hline${ }^{235} \mathrm{U}$ & $+2.3(4.2)$ & +3.5 & +0.8 & +2.3 & $+11(1.0)$ & +12 & +6.7 & +8.2 \\
\hline${ }^{236} \mathrm{U}$ & $-6.2(3.6)$ & +0.1 & +0.9 & +0.0 & $-7.2(2.5)$ & -0.6 & +1.7 & +0.8 \\
\hline${ }^{238} \mathrm{U}$ & $-0.1(2.6)$ & -0.1 & +0.0 & +0.1 & $-0.1(0.2)$ & -0.1 & -0.0 & +0.1 \\
\hline${ }^{237} \mathrm{~Np}$ & $+16(6.0)$ & +10 & +10 & +9.0 & - & - & - & - \\
\hline${ }^{238} \mathrm{Pu}$ & $+2.9(1.9)$ & +0.2 & +14 & +14 & $-5.5(1.5)$ & -7.5 & +4.5 & +4.6 \\
\hline${ }^{239} \mathrm{Pu}$ & $+34(1.3)$ & +14 & +11 & +11 & $+28(0.3)$ & +8.8 & +3.7 & +3.7 \\
\hline${ }^{240} \mathrm{Pu}$ & $+16(1.2)$ & +9.0 & +7.6 & +8.2 & $+7.9(0.3)$ & +1.4 & -0.8 & -0.3 \\
\hline${ }^{241} \mathrm{Pu}$ & $+19(1.2)$ & +9.8 & +9.7 & +9.4 & $+13(0.3)$ & +4.0 & +3.4 & +3.1 \\
\hline${ }^{242} \mathrm{Pu}$ & $+10(12)$ & +13 & +16 & +16 & $-1.8(0.3)$ & +1.2 & +4.8 & +5.0 \\
\hline${ }^{244} \mathrm{Pu}$ & - & - & - & - & $-84(25)$ & -83 & - & -43 \\
\hline${ }^{241} \mathrm{Am}$ & $+4.5(10)$ & -5.1 & -5.9 & -6.0 & $+19(1.8)$ & +7.5 & +5.6 & +5.5 \\
\hline${ }^{242 m} \mathrm{Am}$ & $+11(10)$ & -9.8 & -8.3 & -9.9 & $+31(5.3)$ & +6.1 & +6.7 & +4.8 \\
\hline${ }^{243} \mathrm{Am}$ & $-11(10)$ & -12 & -10 & -10 & $-0.1(1.8)$ & -0.7 & +2.9 & +2.9 \\
\hline${ }^{242} \mathrm{Cm}$ & - & - & - & - & $+3.7(1.8)$ & -4.5 & -6.4 & -7.9 \\
\hline${ }^{243} \mathrm{Cm}$ & - & - & - & - & $-0.9(3.2)$ & -4.7 & -2.4 & -3.5 \\
\hline${ }^{244} \mathrm{Cm}$ & $+10(1.3)$ & +9.0 & +11 & +9.2 & $-0.9(0.9)$ & -0.9 & +5.6 & +3.4 \\
\hline${ }^{245} \mathrm{Cm}$ & $+23(1.5)$ & +15 & +17 & +13 & $+6.0(2.7)$ & +0.6 & +8.1 & +3.7 \\
\hline${ }^{246} \mathrm{Cm}$ & $-7.7(1.8)$ & -3.0 & +2.2 & -3.9 & $-23(10)$ & -18 & -4.5 & -10 \\
\hline
\end{tabular}


Table B.4. Nominal C/E-1 values and experimental uncertainties for fission products in \% $(1 \sigma)$ for the BM1-P and BM1-S samples.

\begin{tabular}{|c|c|c|c|c|c|c|c|c|}
\hline & \multicolumn{4}{|c|}{ BM1-P } & \multicolumn{4}{|c|}{ BM1-S } \\
\hline & \multirow{2}{*}{\multicolumn{2}{|c|}{$\begin{array}{l}\text { CASMO5 } \\
2.03\end{array}$}} & \multicolumn{2}{|c|}{ SNF } & \multirow{2}{*}{\multicolumn{2}{|c|}{$\begin{array}{l}\text { CASMO5 } \\
2.03\end{array}$}} & \multicolumn{2}{|c|}{$\mathrm{SNF}$} \\
\hline & & & 1.6 .4 & 1.07 & & & 1.6 .4 & 1.07 \\
\hline & $\mathrm{C} / \mathrm{E}-1(\Delta \mathrm{E})$ & $\mathrm{C} / \mathrm{E}-1$ & $\mathrm{C} / \mathrm{E}-1$ & $\mathrm{C} / \mathrm{E}-1$ & $\mathrm{C} / \mathrm{E}-1(\Delta \mathrm{E})$ & $\mathrm{C} / \mathrm{E}-1$ & $\mathrm{C} / \mathrm{E}-1$ & $\mathrm{C} / \mathrm{E}-1$ \\
\hline & Pin & Assembly & Core & Core & Pin & Assembly & Core & Core \\
\hline${ }^{90} \mathrm{Sr}$ & $-2.4(5)$ & -2.2 & -0.7 & -1.9 & $-20(7.5)$ & -20 & -16 & -17 \\
\hline${ }^{95} \mathrm{Mo}$ & $+23(1.9)$ & +23 & - & +23 & $+23(6.7)$ & +23 & - & +27 \\
\hline${ }^{99} \mathrm{Tc}$ & $+64(1.4)$ & +64 & +67 & +65 & $+50(14)$ & +50 & +57 & +55 \\
\hline${ }^{101} \mathrm{Ru}$ & $+111(1.8)$ & +111 & - & +112 & $+88(9.2)$ & +89 & - & +94 \\
\hline${ }^{106} \mathrm{Ru}$ & $+239(5.5)$ & +240 & +246 & +245 & $+114(1.7)$ & +104 & +111 & +110 \\
\hline${ }^{103} \mathrm{Rh}$ & $+180(1.5)$ & +177 & - & +178 & $+104(3.9)$ & +102 & - & +107 \\
\hline${ }^{109} \mathrm{Ag}$ & $+77(1.0)$ & +77 & - & +26 & $+65(8.3)$ & +67 & - & +21 \\
\hline${ }^{125} \mathrm{Sb}$ & $+78(2.2)$ & +78 & +77 & +81 & $+75(3.0)$ & +76 & +77 & +80 \\
\hline${ }^{144} \mathrm{Ce}$ & $+8.4(5.5)$ & +8.4 & +13 & +13 & $+1.5(4.5)$ & +2.0 & +5.0 & +4.9 \\
\hline${ }^{133} \mathrm{Cs}$ & $-2.4(2.1)$ & -2.6 & - & -2.0 & $+2.5(1.0)$ & +3.0 & - & +5.8 \\
\hline${ }^{134} \mathrm{Cs}$ & $-9.7(2.3)$ & -10 & -7.3 & -9.5 & $-6.5(1.0)$ & -5.8 & +1.2 & -1.2 \\
\hline${ }^{135} \mathrm{Cs}$ & $+2.3(2.2)$ & -5.5 & -4.0 & -6.1 & $+11(1.0)$ & +3.2 & +7.0 & +4.7 \\
\hline${ }^{137} \mathrm{Cs}$ & $-8.1(2.0)$ & -8.2 & -6.3 & -7.6 & $-1.6(1.0)$ & -1.0 & +3.4 & +1.9 \\
\hline${ }^{142} \mathrm{Nd}$ & $+4.0(4.9)$ & +7.9 & - & +9.6 & $-10(5.0)$ & -5.6 & - & +4.0 \\
\hline${ }^{143} \mathrm{Nd}$ & $+7.9(4.9)$ & +5.9 & - & +6.1 & $+4.3(0.3)$ & +3.0 & - & +1.2 \\
\hline${ }^{144} \mathrm{Nd}$ & $+1.1(4.9)$ & +2.6 & - & +4.2 & $-3.7(0.3)$ & -1.5 & - & +5.1 \\
\hline${ }^{145} \mathrm{Nd}$ & $+2.4(5.0)$ & +2.2 & - & +2.7 & $+0.2(0.3)$ & +0.6 & - & +3.0 \\
\hline${ }^{146} \mathrm{Nd}$ & $+1.5(5.0)$ & +1.5 & - & +1.9 & $-0.6(0.3)$ & +0.3 & - & +3.3 \\
\hline${ }^{148} \mathrm{Nd}$ & $+0.9(5.0)$ & +0.8 & +2.8 & +1.4 & $+0.2(0.3)$ & +0.9 & +5.5 & +3.5 \\
\hline${ }^{150} \mathrm{Nd}$ & $+0.4(5.1)$ & +0.2 & - & +0.9 & $+0.6(0.3)$ & +1.1 & - & +4.3 \\
\hline${ }^{147} \mathrm{Pm}$ & - & - & - & - & $+4.0(4.2)$ & +0.3 & - & +4.0 \\
\hline${ }^{147} \mathrm{Sm}$ & $+0.7(2.2)$ & +0.1 & +1.9 & +1.3 & $-3.1(0.3)$ & -3.3 & -0.4 & -1.0 \\
\hline${ }^{148} \mathrm{Sm}$ & $-1.1(2.0)$ & -3.0 & - & -2.4 & $-3.6(0.3)$ & -4.3 & - & +0.0 \\
\hline${ }^{149} \mathrm{Sm}$ & $+25(5.5)$ & +8.3 & - & +8.2 & $+27(1.1)$ & +9.5 & - & +8.6 \\
\hline${ }^{150} \mathrm{Sm}$ & $-1.0(2.1)$ & -0.5 & - & -0.1 & $-1.5(0.3)$ & -0.1 & - & +2.8 \\
\hline${ }^{151} \mathrm{Sm}$ & $+13.9(2.3)$ & +0.1 & -0.6 & -1.7 & $+16(0.4)$ & +2.3 & +1.1 & +0.1 \\
\hline${ }^{152} \mathrm{Sm}$ & $-5.1(2.0)$ & -4.3 & - & -2.9 & $-7.8(0.3)$ & -6.7 & - & -4.3 \\
\hline${ }^{154} \mathrm{Sm}$ & $-3.6(2.1)$ & -3.1 & - & -2.6 & $-4.7(0.4)$ & -3.9 & - & -0.9 \\
\hline${ }^{153} \mathrm{Eu}$ & $+0.5(1.9)$ & +0.5 & - & +1.2 & $-2.6(0.4)$ & -1.9 & - & +1.2 \\
\hline${ }^{154} \mathrm{Eu}$ & $-3.6(2.1)$ & -7.2 & -4.8 & -7.7 & $+11(1.5)$ & +8.4 & +15 & +11 \\
\hline${ }^{155} \mathrm{Eu}$ & $-23(2.8)$ & -23 & -23 & -23 & $-15(2.3)$ & -14 & -10 & -11 \\
\hline${ }^{154} \mathrm{Gd}$ & $+12(1.5)$ & +7.9 & - & +7.0 & - & - & - & - \\
\hline${ }^{155} \mathrm{Gd}$ & $+0.2(1.8)$ & -0.0 & - & -0.0 & $+2.4(2.5)$ & +3.0 & - & +6.4 \\
\hline${ }^{156} \mathrm{Gd}$ & $-9.2(0.7)$ & -5.3 & - & -4.0 & - & - & - & - \\
\hline${ }^{158} \mathrm{Gd}$ & $+7.7(1.1)$ & +8.4 & - & +8.7 & - & - & - & - \\
\hline${ }^{160} \mathrm{Gd}$ & $-1.3(3.4)$ & -1.2 & - & -0.2 & - & - & - & - \\
\hline
\end{tabular}


Table B.5. Nominal $\mathrm{C} / \mathrm{E}-1$ values in $\%$ for the BM3 sample. No experimental uncertainties are reported in the ARIANE report [3].

\begin{tabular}{llll|llll}
\hline & CASMO5 2.03 & SNF-1.6.4 & SNF-1.07 & & CASMO5 2.03 & SNF-1.6.4 & SNF-1.07 \\
& C/E-1 & C/E-1 & C/E-1 & & C/E-1 $(\Delta \mathrm{E})$ & C/E-1 & C/E-1 \\
& Assembly & Core & Core & & Assembly & Core & Core \\
\hline${ }^{234} \mathrm{U}$ & -19.2 & -13.6 & -15.1 & ${ }^{235} \mathrm{U}$ & -2.6 & -2.7 & +0.7 \\
${ }^{236} \mathrm{U}$ & -1.0 & -1.1 & -3.1 & ${ }^{238} \mathrm{U}$ & +0.0 & +0.1 & +0.2 \\
${ }^{238} \mathrm{Pu}$ & -12.2 & -2.5 & -3.4 & ${ }^{239} \mathrm{Pu}$ & -1.4 & -2.0 & -0.4 \\
${ }^{240} \mathrm{Pu}$ & -6.4 & -6.3 & -5.3 & ${ }^{241} \mathrm{Pu}$ & -2.5 & -2.7 & -2.6 \\
${ }^{242} \mathrm{Pu}$ & -0.9 & -0.8 & -1.9 & & & & \\
\hline${ }^{142} \mathrm{Nd}$ & +6.3 & - & -1.3 & ${ }^{143} \mathrm{Nd}$ & -1.7 & - & -4.6 \\
${ }^{144} \mathrm{Nd}$ & -3.1 & - & +6.5 & ${ }^{145} \mathrm{Nd}$ & -2.1 & - & -2.3 \\
${ }^{146} \mathrm{Nd}$ & -2.6 & - & -6.6 & ${ }^{148} \mathrm{Nd}$ & +1.4 & +1.2 & -2.3 \\
${ }^{150} \mathrm{Nd}$ & -3.4 & - & -6.8 & & & & \\
\hline
\end{tabular}

Table B.6. Uncertainties in \% at the time of measurement due to the ENDF/B-VIII.0 library with the three models (pin, assembly and core) for the BM1-P sample, based on the CASMO5 v2.03 calculations.

\begin{tabular}{llll|llll}
\hline & Pin & Assembly & core & & Pin & Assembly & core \\
\hline${ }^{234} \mathrm{U}$ & 5.4 & 2.0 & 2.6 & ${ }^{235} \mathrm{U}$ & 1.2 & 0.8 & 0.9 \\
${ }^{236} \mathrm{U}$ & 2.9 & 0.9 & 0.9 & ${ }^{238} \mathrm{U}$ & 0.1 & 0.0 & 0.0 \\
${ }^{237} \mathrm{~Np}$ & 5.9 & 5.9 & 5.8 & ${ }^{238} \mathrm{Pu}$ & 2.9 & 3.2 & 2.8 \\
${ }^{239} \mathrm{Pu}$ & 1.7 & 1.8 & 1.7 & ${ }^{240} \mathrm{Pu}$ & 3.2 & 2.2 & 2.8 \\
${ }^{241} \mathrm{Pu}$ & 2.7 & 1.7 & 1.3 & ${ }^{242} \mathrm{Pu}$ & 4.9 & 3.8 & 3.9 \\
${ }^{241} \mathrm{Am}$ & 3.2 & 1.9 & 1.9 & ${ }^{242 m} \mathrm{Am}$ & 1.9 & 1.9 & 1.8 \\
${ }^{243} \mathrm{Am}$ & 6.6 & 6.2 & 6.0 & ${ }^{244} \mathrm{Cm}$ & 7.3 & 6.8 & 6.5 \\
${ }^{245} \mathrm{Cm}$ & 13 & 12 & 12 & ${ }^{246} \mathrm{Cm}$ & 22 & 23 & 21 \\
\hline${ }^{90} \mathrm{Sr}$ & 1.2 & 1.1 & 1.6 & ${ }^{95} \mathrm{Mo}$ & 5.6 & 1.1 & - \\
${ }^{99} \mathrm{Tc}$ & 6.1 & 2.6 & 2.8 & ${ }^{101} \mathrm{Ru}$ & 7.5 & 5.0 & - \\
${ }^{106} \mathrm{Ru}$ & 5.2 & 1.4 & 1.9 & ${ }^{103} \mathrm{Rh}$ & 3.7 & 1.8 & - \\
${ }^{109} \mathrm{Ag}$ & 22 & 24 & - & ${ }^{125} \mathrm{Sb}$ & 24 & 22 & 25 \\
${ }^{144} \mathrm{Ce}$ & 5.3 & 0.5 & 1.3 & ${ }^{133} \mathrm{Cs}$ & 33 & 33 & - \\
${ }^{134} \mathrm{Cs}$ & 47 & 33 & 34 & ${ }^{135} \mathrm{Cs}$ & 12 & 12 & 13 \\
${ }^{137} \mathrm{Cs}$ & 7.1 & 6.8 & 6.8 & ${ }^{142} \mathrm{Nd}$ & 7.5 & 7.1 & - \\
${ }^{143} \mathrm{Nd}$ & 1.5 & 1.4 & - & ${ }^{144} \mathrm{Nd}$ & 1.9 & 1.0 & - \\
${ }^{145} \mathrm{Nd}$ & 1.6 & 1.5 & - & ${ }^{146} \mathrm{Nd}$ & 1.5 & 1.4 & - \\
${ }^{148} \mathrm{Nd}$ & 0.5 & 0.5 & 1.1 & ${ }^{150} \mathrm{Nd}$ & 0.5 & 0.6 & - \\
${ }^{147} \mathrm{Sm}$ & 4.6 & 2.6 & 2.6 & ${ }^{148} \mathrm{Sm}$ & 2.6 & 2.4 & - \\
${ }^{149} \mathrm{Sm}$ & 2.5 & 2.2 & - & ${ }^{150} \mathrm{Sm}$ & 1.6 & 1.5 & - \\
${ }^{151} \mathrm{Sm}$ & 3.2 & 3.2 & 3.3 & ${ }^{152} \mathrm{Sm}$ & 2.9 & 2.8 & - \\
${ }^{154} \mathrm{Sm}$ & 2.1 & 2.0 & - & ${ }^{153} \mathrm{Eu}$ & 3.3 & 3.3 & - \\
${ }^{154} \mathrm{Eu}$ & 6.0 & 4.2 & 4.2 & ${ }^{155} \mathrm{Eu}$ & 29 & 27 & 30 \\
${ }^{154} \mathrm{Gd}$ & 6.6 & 4.4 & - & ${ }^{155} \mathrm{Gd}$ & 29 & 27 & - \\
${ }^{156} \mathrm{Gd}$ & 5.0 & 4.8 & - & ${ }^{158} \mathrm{Gd}$ & 1.4 & 1.2 & - \\
${ }^{160} \mathrm{Gd}$ & 9.2 & 9.8 & - & & & & \\
\hline
\end{tabular}


Table B.7. Comparison in \% between the impact of the nuclear data libraries for the BM1-P sample with the assembly model, based on the CASMO5 v2.03 calculations. Value are at the time of measurement.

\begin{tabular}{|c|c|c|c|c|c|c|c|}
\hline & ENDF/B-VIII.0 & JEFF-3.3 & JENDL-4.0 & & ENDF/B-VIII.0 & JEFF-3.3 & JENDL-4.0 \\
\hline${ }^{234} \mathrm{U}$ & 2.0 & 4.0 & 4.5 & ${ }^{235} \mathrm{U}$ & 0.8 & 1.1 & 1.0 \\
\hline${ }^{236} \mathrm{U}$ & 0.9 & 1.7 & 1.1 & ${ }^{238} \mathrm{U}$ & 0.0 & 0.0 & 0.0 \\
\hline${ }^{237} \mathrm{~Np}$ & 5.9 & 18 & 18 & ${ }^{238} \mathrm{Pu}$ & 3.2 & 8.0 & 5.3 \\
\hline${ }^{239} \mathrm{Pu}$ & 1.8 & 1.7 & 2.0 & ${ }^{240} \mathrm{Pu}$ & 2.2 & 1.5 & 2.8 \\
\hline${ }^{241} \mathrm{Pu}$ & 1.7 & 2.6 & 3.2 & ${ }^{242} \mathrm{Pu}$ & 3.8 & 6.2 & 6.1 \\
\hline${ }^{241} \mathrm{Am}$ & 1.9 & 2.4 & 3.6 & ${ }^{242 m} \mathrm{Am}$ & 1.9 & 2.1 & 3.5 \\
\hline${ }^{243} \mathrm{Am}$ & 6.2 & 3.8 & 4.9 & ${ }^{244} \mathrm{Cm}$ & 6.8 & 4.2 & 5.4 \\
\hline${ }^{245} \mathrm{Cm}$ & 12 & 9.6 & 11 & ${ }^{246} \mathrm{Cm}$ & 23 & 15 & 21 \\
\hline${ }^{90} \mathrm{Sr}$ & 1.1 & 1.5 & 1.1 & ${ }^{95} \mathrm{Mo}$ & 1.1 & 0.9 & 1.1 \\
\hline${ }^{99} \mathrm{Tc}$ & 2.6 & 1.1 & 2.4 & ${ }^{101} \mathrm{Ru}$ & 5.0 & 1.3 & 4.7 \\
\hline${ }^{106} \mathrm{Ru}$ & 1.4 & 1.8 & 1.4 & ${ }^{103} \mathrm{Rh}$ & 1.8 & 1.5 & 1.6 \\
\hline${ }^{109} \mathrm{Ag}$ & 24 & 4.3 & 22 & ${ }^{125} \mathrm{Sb}$ & 22 & 35 & 35 \\
\hline${ }^{133} \mathrm{Cs}$ & 33 & 2.9 & 37 & ${ }^{134} \mathrm{Cs}$ & 33 & 5.0 & 35 \\
\hline${ }^{135} \mathrm{Cs}$ & 12 & 13 & 13 & ${ }^{137} \mathrm{Cs}$ & 6.8 & 4.4 & 6.8 \\
\hline${ }^{144} \mathrm{Ce}$ & 0.5 & 0.9 & 0.5 & ${ }^{142} \mathrm{Nd}$ & 7.1 & 7.0 & 0.9 \\
\hline${ }^{143} \mathrm{Nd}$ & 1.4 & 1.6 & 0.6 & ${ }^{144} \mathrm{Nd}$ & 1.0 & 1.3 & 0.4 \\
\hline${ }^{145} \mathrm{Nd}$ & 1.5 & 1.1 & 0.6 & ${ }^{146} \mathrm{Nd}$ & 1.4 & 0.8 & 0.5 \\
\hline${ }^{148} \mathrm{Nd}$ & 0.5 & 0.8 & 0.5 & ${ }^{150} \mathrm{Nd}$ & 0.6 & 1.1 & 0.6 \\
\hline${ }^{147} \mathrm{Sm}$ & 2.6 & 1.5 & 1.7 & ${ }^{148} \mathrm{Sm}$ & 2.4 & 1.6 & 1.8 \\
\hline${ }^{149} \mathrm{Sm}$ & 2.2 & 4.1 & 1.8 & ${ }^{150} \mathrm{Sm}$ & 1.5 & 1.7 & 1.5 \\
\hline${ }^{151} \mathrm{Sm}$ & 3.2 & 12 & 2.5 & ${ }^{152} \mathrm{Sm}$ & 2.8 & 4.2 & 1.6 \\
\hline${ }^{154} \mathrm{Sm}$ & 2.0 & 11 & 1.8 & ${ }^{153} \mathrm{Eu}$ & 3.3 & 3.5 & 1.3 \\
\hline${ }^{154} \mathrm{Eu}$ & 4.2 & 3.9 & 1.6 & ${ }^{155} \mathrm{Eu}$ & 27 & 33 & 1.5 \\
\hline${ }^{154} \mathrm{Gd}$ & 4.4 & 4.2 & 1.6 & ${ }^{155} \mathrm{Gd}$ & 27 & 33 & 1.5 \\
\hline${ }^{156} \mathrm{Gd}$ & 4.8 & 6.5 & 2.7 & ${ }^{158} \mathrm{Gd}$ & 1.2 & 3.3 & 0.9 \\
\hline${ }^{160} \mathrm{Gd}$ & 9.2 & 27 & 8.6 & & & & \\
\hline
\end{tabular}

Table B.8. Comparison of uncertainties (in \%) from nuclear data FY and XS between the assembly (2D) and full core (3D) models. Uncertainties are given in \% $(1 \sigma)$. The term FY corresponds to fission yields, and XS to the rest of nuclear data. Values are provided at the time of measurement.

\begin{tabular}{|c|c|c|c|c|c|c|c|c|c|}
\hline & FY & & $\mathrm{XS}$ & & & FY & & $\mathrm{XS}$ & \\
\hline & Assembly & core & Assembly & core & & Assembly & core & Assembly & core \\
\hline${ }^{234} \mathrm{U}$ & 0.3 & 0.1 & 1.9 & 2.6 & ${ }^{235} \mathrm{U}$ & 0.1 & 0.2 & 0.7 & 0.9 \\
\hline${ }^{236} \mathrm{U}$ & 0.1 & 0.1 & 0.9 & 0.9 & ${ }^{238} \mathrm{U}$ & 0.0 & 0.0 & 0.0 & 0.0 \\
\hline${ }^{237} \mathrm{~Np}$ & 0.1 & 0.1 & 5.9 & 5.8 & ${ }^{238} \mathrm{Pu}$ & 0.1 & 0.1 & 3.1 & 2.8 \\
\hline${ }^{239} \mathrm{Pu}$ & 0.2 & 0.2 & 1.7 & 1.7 & ${ }^{240} \mathrm{Pu}$ & 0.1 & 0.1 & 2.1 & 2.8 \\
\hline${ }^{241} \mathrm{Pu}$ & 0.2 & 0.1 & 1.7 & 1.4 & ${ }^{242} \mathrm{Pu}$ & 0.1 & 0.1 & 3.8 & 3.7 \\
\hline${ }^{241} \mathrm{Am}$ & 0.1 & 0.1 & 1.9 & 1.8 & ${ }^{242 m} \mathrm{Am}$ & 0.2 & 0.2 & 1.9 & 1.8 \\
\hline${ }^{243} \mathrm{Am}$ & 0.7 & 0.1 & 6.2 & 5.9 & ${ }^{244} \mathrm{Cm}$ & 0.2 & 0.3 & 6.8 & 6.4 \\
\hline${ }^{245} \mathrm{Cm}$ & 0.4 & 0.3 & 12 & 12 & ${ }^{246} \mathrm{Cm}$ & 0.2 & 0.4 & 23 & 21 \\
\hline${ }^{90} \mathrm{Sr}$ & 1.0 & 1.1 & 0.1 & 1.0 & ${ }^{99} \mathrm{Tc}$ & 2.3 & 2.3 & 0.4 & 1.8 \\
\hline${ }^{106} \mathrm{Ru}$ & 1.4 & 1.1 & 0.1 & 1.5 & ${ }^{125} \mathrm{Sb}$ & 22 & 25 & 0.4 & 1.3 \\
\hline${ }^{144} \mathrm{Ce}$ & 0.5 & 0.6 & 0.1 & 1.1 & ${ }^{134} \mathrm{Cs}$ & 33 & 33 & 5.2 & 4.8 \\
\hline${ }^{135} \mathrm{Cs}$ & 12 & 13 & 0.7 & 1.2 & ${ }^{137} \mathrm{Cs}$ & 6.8 & 6.8 & 0.1 & 1.1 \\
\hline${ }^{148} \mathrm{Nd}$ & 0.5 & 0.5 & 0.1 & 1.1 & ${ }^{147} \mathrm{Sm}$ & 1.7 & 1.5 & 1.9 & 1.9 \\
\hline${ }^{151} \mathrm{Sm}$ & 2.2 & 1.9 & 2.3 & 2.2 & ${ }^{154} \mathrm{Eu}$ & 1.5 & 1.5 & 3.4 & 3.5 \\
\hline${ }^{155} \mathrm{Eu}$ & 1.6 & 1.5 & 27 & 29 & & & & & \\
\hline
\end{tabular}


Table B.9. Summary of all uncertainties in \% (or $1 \sigma)$ for the BM1-P sample with the assembly model considered in this study for actinides. For nuclear data, the range from Table B.7 is presented here. The "Sum" column corresponds to $\sqrt{\sum_{i} \Delta^{2}\left(C_{i}\right)}$ for calculated uncertainties. The sums for the GU1 and GU3 samples are also indicated (without the systematic effect of $2 \%$ for the mass balance of GU1). See text for the description of the columns.

\begin{tabular}{|c|c|c|c|c|c|c|c|c|c|c|c|c|c|}
\hline & $\begin{array}{l}\text { C/E-1 }(\Delta \mathrm{E}) \\
\text { BM1-P }\end{array}$ & $\begin{array}{l}\mathrm{ND} \\
\min -\max \end{array}$ & TFU & TMO & BOR & RAD & $\begin{array}{l}\text { ENR } \\
+ \text { DEN }\end{array}$ & $(\mathrm{X}-\mathrm{Y})$ & DEP & PITCH & $\begin{array}{l}\text { Sum }_{\mathrm{BM} 1-\mathrm{P}} \\
\min -\max \end{array}$ & $\begin{array}{l}\text { Sum }_{\text {GU } 3} \\
\min -\max \end{array}$ & $\begin{array}{l}\mathrm{Sum}_{\mathrm{GU} 1} \\
\min -\max \end{array}$ \\
\hline${ }^{234} \mathrm{U}$ & $-9.8(13.3)$ & $1.9-4.5$ & 0.0 & 0.1 & 0.0 & 0.1 & 0.2 & 0.0 & 0.1 & 0.7 & $2.0-4.6$ & $2.3-7.9$ & $0.9-10.0$ \\
\hline${ }^{235} \mathrm{U}$ & $+3.5(4.2)$ & $0.8-1.1$ & 0.1 & 0.4 & 0.0 & 0.3 & 0.3 & 0.9 & 0.2 & 0.6 & $1.5-1.7$ & $2.8-3.1$ & $5.4-6.3$ \\
\hline${ }^{236} \mathrm{U}$ & $+0.1(3.6)$ & $0.9-1.7$ & 0.0 & 0.1 & 0.0 & 0.1 & 0.1 & 0.3 & 0.1 & 0.4 & $1.0-1.8$ & $0.9-1.7$ & $0.7-1.7$ \\
\hline${ }^{238} \mathrm{U}$ & $-0.1(2.6)$ & 0.0 & 0.1 & 0.0 & 0.0 & 0.0 & 0.0 & 0.0 & 0.0 & 0.0 & $0.1-0.1$ & $0.0-0.0$ & $0.0-0.0$ \\
\hline${ }^{237} \mathrm{~Np}$ & $+10(6.0)$ & $5.9-18$ & 0.0 & 0.6 & 0.0 & 0.1 & 0.1 & 0.1 & 0.1 & 0.8 & $6.0-18$ & $3.7-4.2$ & - \\
\hline${ }^{238} \mathrm{Pu}$ & $+0.2(1.9)$ & $3.2-8.0$ & 0.0 & 0.4 & 0.0 & 0.1 & 0.2 & 0.1 & 0.1 & 0.6 & $3.3-8.0$ & $5.6-10$ & $3.5-13.4$ \\
\hline${ }^{239} \mathrm{Pu}$ & $+14(1.3)$ & $1.7-2.0$ & 0.1 & 1.2 & 0.0 & 0.5 & 0.5 & 1.3 & 0.1 & 1.3 & $2.9-3.1$ & $2.9-3.2$ & $2.8-3.3$ \\
\hline${ }^{240} \mathrm{Pu}$ & $+9.0(1.2)$ & $1.5-2.8$ & 0.0 & 0.1 & 0.0 & 0.1 & 0.3 & 0.4 & 0.1 & 0.3 & $1.6-2.9$ & $2.8-4.5$ & $2.6-5.0$ \\
\hline${ }^{241} \mathrm{Pu}$ & $+9.8(2.3)$ & $1.7-3.2$ & 0.0 & 0.7 & 0.0 & 0.1 & 0.3 & 0.3 & 0.0 & 0.6 & $2.0-3.4$ & $3.8-4.2$ & $4.0-4.5$ \\
\hline${ }^{242} \mathrm{Pu}$ & $+13(12)$ & $3.8-6.1$ & 0.1 & 0.4 & 0.0 & 0.3 & 0.2 & 0.7 & 0.1 & 0.5 & $3.9-6.2$ & $5.1-8.7$ & $5.2-8.8$ \\
\hline${ }^{241} \mathrm{Am}$ & $-5.1(10)$ & $1.9-3.6$ & 0.1 & 0.6 & 0.0 & 0.2 & 0.2 & 0.5 & 0.0 & 0.7 & $2.2-3.8$ & $4.5-5.1$ & $4.2-5.0$ \\
\hline${ }^{242 m} \mathrm{Am}$ & $-9.8(10)$ & $1.9-3.5$ & 0.1 & 1.8 & 0.0 & 0.6 & 0.5 & 1.3 & 0.1 & 1.9 & $3.6-4.6$ & $5.8-6.6$ & $6.3-6.6$ \\
\hline${ }^{243} \mathrm{Am}$ & $-12(10)$ & $3.8-6.2$ & 0.1 & 0.2 & 0.0 & 0.3 & 0.4 & 0.7 & 0.1 & 0.7 & $4.0-6.3$ & $8.1-9.3$ & $7.7-9.0$ \\
\hline${ }^{244} \mathrm{Cm}$ & $+9.0(1.3)$ & $4.2-6.8$ & 0.1 & 0.8 & 0.0 & 0.4 & 0.5 & 0.8 & 0.3 & 1.5 & $4.7-7.1$ & $10-11$ & $9.3-10.3$ \\
\hline${ }^{245} \mathrm{Cm}$ & $+15(1.5)$ & $9.6-12$ & 0.1 & 2.4 & 0.0 & 0.4 & 0.5 & 0.6 & 0.3 & 2.7 & $10-13$ & $16-17$ & $14.0-16.0$ \\
\hline${ }^{246} \mathrm{Cm}$ & $-3.0(1.8)$ & $15-23$ & 0.1 & 1.1 & 0.0 & 0.8 & 1.0 & 1.9 & 0.6 & 2.6 & $15-23$ & $21-25$ & $14.5-24.5$ \\
\hline
\end{tabular}

Table B.10. Same as Table B.9, but for fission products.

\begin{tabular}{|c|c|c|c|c|c|c|c|c|c|c|c|c|c|}
\hline & $\begin{array}{l}\text { C/E-1 }(\Delta \mathrm{E}) \\
\text { BM1-P }\end{array}$ & $\begin{array}{l}\mathrm{ND} \\
\min -\max \end{array}$ & TFU & TMO & BOR & RAD & $\begin{array}{l}\text { ENR } \\
+ \text { DEN }\end{array}$ & $(\mathrm{X}-\mathrm{Y})$ & DEP & PITCH & $\begin{array}{l}\text { SumBM1-P } \\
\min -\max \end{array}$ & $\begin{array}{l}\text { SumGU3 } \\
\min -\max \end{array}$ & $\begin{array}{l}\text { SumGU1 } \\
\min -\max \end{array}$ \\
\hline${ }^{90} \mathrm{Sr}$ & $-2.2(5)$ & $1.1-1.5$ & 0.0 & 0.1 & 0.0 & 0.3 & 0.3 & 0.6 & 0.1 & 0.5 & $1.4-1.7$ & $0.8-1.4$ & $0.9-1.5$ \\
\hline${ }^{95} \mathrm{Mo}$ & $+23(1.9)$ & $0.9-1.1$ & 0.0 & 0.0 & 0.0 & 0.3 & 0.3 & 0.6 & 0.1 & 0.5 & $1.3-1.4$ & $0.9-1.1$ & $0.9-1.0$ \\
\hline${ }^{99} \mathrm{Tc}$ & $+64(1.4)$ & $1.1-2.6$ & 0.0 & 0.1 & 0.0 & 0.3 & 0.3 & 0.6 & 0.1 & 0.5 & $1.4-2.8$ & $0.9-1.7$ & $1.0-1.7$ \\
\hline${ }^{101} \mathrm{Ru}$ & $+111(2.3)$ & $1.3-5.0$ & 0.0 & 0.1 & 0.0 & 0.3 & 0.3 & 0.7 & 0.1 & 0.5 & $1.6-5.1$ & $1.1-3.1$ & $1.3-3.5$ \\
\hline${ }^{106} \mathrm{Ru}$ & $+239(5.5)$ & $1.4-1.8$ & 0.0 & 0.0 & 0.0 & 0.3 & 0.4 & 0.6 & 0.1 & 0.6 & $1.7-2.1$ & $1.8-1.9$ & $1.6-2.0$ \\
\hline${ }^{103} \mathrm{Rh}$ & $+180(1.5)$ & $1.5-1.8$ & 0.0 & 0.1 & 0.0 & 0.2 & 0.3 & 0.4 & 0.1 & 0.4 & $1.6-1.9$ & $1.4-1.8$ & $1.6-2.1$ \\
\hline${ }^{109} \mathrm{Ag}$ & $+77(1.0)$ & $4.3-24$ & 0.0 & 0.1 & 0.0 & 0.3 & 0.4 & 0.8 & 0.2 & 0.5 & $4.4-24$ & $4.6-21$ & $5.1-21.0$ \\
\hline${ }^{125} \mathrm{Sb}$ & $+78(2.2)$ & $22-35$ & 0.0 & 0.0 & 0.0 & 0.3 & 0.3 & 0.5 & 0.1 & 0.4 & $22-35$ & $18.0-30.3$ & $18.5-32.0$ \\
\hline${ }^{133} \mathrm{Cs}$ & $-2.6(2.1)$ & $2.9-37$ & 0.0 & 0.1 & 0.0 & 0.3 & 0.3 & 0.6 & 0.1 & 0.4 & $3.0-37$ & $2.3-30.5$ & $2.4-29.4$ \\
\hline${ }^{134} \mathrm{Cs}$ & $-10(2.3)$ & $5.0-35$ & 0.0 & 0.9 & 0.0 & 0.4 & 0.5 & 1.0 & 0.3 & 1.1 & $5.3-35$ & $4.9-30.3$ & $4.5-28.0$ \\
\hline${ }^{135} \mathrm{Cs}$ & $-5.5(2.2)$ & $12-13$ & 0.0 & 0.7 & 0.0 & 0.1 & 0.2 & 0.1 & 0.1 & 1.1 & $12-13$ & $7.5-19.9$ & $5.3-19.1$ \\
\hline${ }^{137} \mathrm{Cs}$ & $-8.2(2.0)$ & $4.4-6.8$ & 0.0 & 0.1 & 0.0 & 0.3 & 0.3 & 0.7 & 0.1 & 0.5 & $4.5-6.9$ & $3.6-6.9$ & $3.6-6.5$ \\
\hline${ }^{144} \mathrm{Ce}$ & $+8.4(5.5)$ & $0.5-0.9$ & 0.0 & 0.0 & 0.0 & 0.3 & 0.3 & 0.5 & 0.1 & 0.6 & $1.0-1.3$ & $0.9-1.0$ & $0.9-1.0$ \\
\hline${ }^{142} \mathrm{Nd}$ & $+7.9(4.9)$ & $0.9-7.1$ & 0.0 & 0.4 & 0.0 & 0.6 & 0.6 & 1.4 & 0.3 & 1.4 & $2.4-7.4$ & $1.7-5.3$ & $2.5-4.7$ \\
\hline${ }^{143} \mathrm{Nd}$ & $+5.9(4.9)$ & $0.6-1.6$ & 0.0 & 0.2 & 0.0 & 0.2 & 0.3 & 0.4 & 0.1 & 0.5 & $1.0-1.8$ & $1.3-3.7$ & $1.9-5.2$ \\
\hline${ }^{144} \mathrm{Nd}$ & $+2.6(4.9)$ & $0.4-1.3$ & 0.0 & 0.1 & 0.0 & 0.4 & 0.4 & 0.9 & 0.2 & 0.7 & $1.4-1.8$ & $1.1-2.4$ & $1.1-2.2$ \\
\hline${ }^{145} \mathrm{Nd}$ & $+2.2(5.0)$ & $0.6-1.5$ & 0.0 & 0.1 & 0.0 & 0.3 & 0.3 & 0.6 & 0.1 & 0.5 & $1.1-1.7$ & $0.7-2.0$ & $0.7-2.4$ \\
\hline${ }^{146} \mathrm{Nd}$ & $+1.5(5.0)$ & $0.5-1.4$ & 0.0 & 0.1 & 0.0 & 0.3 & 0.3 & 0.7 & 0.2 & 0.7 & $1.2-1.8$ & $0.8-1.9$ & $1.0-1.9$ \\
\hline${ }^{148} \mathrm{Nd}$ & $+0.9(5.0)$ & $0.5-0.8$ & 0.0 & 0.0 & 0.0 & 0.3 & 0.3 & 0.7 & 0.2 & 0.6 & $1.1-1.3$ & $0.9-0.9$ & $0.9-1.0$ \\
\hline${ }^{150} \mathrm{Nd}$ & $+0.2(5.1)$ & $0.6-1.1$ & 0.0 & 0.0 & 0.0 & 0.3 & 0.3 & 0.7 & 0.2 & 0.6 & $1.2-1.5$ & $1.0-1.2$ & $0.9-1.2$ \\
\hline${ }^{147} \mathrm{Sm}$ & $+0.1(2.2)$ & $1.5-2.6$ & 0.0 & 0.4 & 0.0 & 0.2 & 0.2 & 0.4 & 0.1 & 0.3 & $1.7-2.7$ & $1.4-2.4$ & $1.3-2.5$ \\
\hline${ }^{148} \mathrm{Sm}$ & $-3.0(2.0)$ & $1.6-2.4$ & 0.0 & 0.6 & 0.0 & 0.3 & 0.4 & 0.8 & 0.2 & 1.3 & $2.4-3.0$ & $1.7-2.4$ & $1.6-2.4$ \\
\hline${ }^{149} \mathrm{Sm}$ & $+8.3(5.5)$ & $1.8-4.1$ & 0.1 & 2.3 & 0.0 & 0.2 & 0.4 & 0.7 & 0.0 & 1.2 & $3.3-4.9$ & $3.3-4.5$ & $2.5-3.9$ \\
\hline${ }^{150} \mathrm{Sm}$ & $-0.5(2.1)$ & $1.5-1.7$ & 0.0 & 0.1 & 0.0 & 0.3 & 0.3 & 0.7 & 0.1 & 0.6 & $1.8-2.0$ & $1.3-1.5$ & $1.2-1.7$ \\
\hline${ }^{151} \mathrm{Sm}$ & $+0.1(2.3)$ & $2.5-12$ & 0.0 & 2.2 & 0.0 & 0.3 & 0.3 & 0.7 & 0.0 & 1.3 & $3.7-12$ & $4.0-12.5$ & $3.7-13.1$ \\
\hline${ }^{152} \mathrm{Sm}$ & $-4.3(2.0)$ & $1.6-4.2$ & 0.0 & 0.9 & 0.0 & 0.3 & 0.3 & 0.5 & 0.1 & 0.5 & $2.0-4.4$ & $1.6-4.0$ & $1.5-4.0$ \\
\hline${ }^{154} \mathrm{Sm}$ & $-3.1(2.1)$ & $1.8-11$ & 0.0 & 0.0 & 0.0 & 0.3 & 0.4 & 0.7 & 0.1 & 0.6 & $2.1-11$ & $2.0-7.4$ & $2.0-7.9$ \\
\hline${ }^{153} \mathrm{Eu}$ & $+0.5(1.9)$ & $1.3-3.5$ & 0.0 & 0.2 & 0.0 & 0.3 & 0.4 & 0.7 & 0.2 & 0.6 & $1.7-3.7$ & $1.3-3.4$ & $1.3-3.4$ \\
\hline${ }^{154} \mathrm{Eu}$ & $-7.2(2.1)$ & $1.6-4.2$ & 0.0 & 1.2 & 0.0 & 0.3 & 0.3 & 0.5 & 0.2 & 1.4 & $2.5-4.6$ & $2.7-3.7$ & $2.3-2.8$ \\
\hline${ }^{155} \mathrm{Eu}$ & $-23(2.8)$ & $1.5-33$ & 0.0 & 0.6 & 0.0 & 0.4 & 0.5 & 0.8 & 0.2 & 0.8 & $2.1-33$ & $1.5-23.7$ & $1.3-19.3$ \\
\hline${ }^{154} \mathrm{Gd}$ & $+7.9(1.5)$ & $1.6-4.4$ & 0.0 & 1.1 & 0.0 & 0.3 & 0.3 & 0.6 & 0.2 & 1.6 & $2.6-4.9$ & - & - \\
\hline${ }^{155} \mathrm{Gd}$ & $-0.0(1.8)$ & $1.5-33$ & 0.0 & 0.6 & 0.0 & 0.4 & 0.4 & 0.7 & 0.2 & 0.8 & $2.0-33$ & $4.0-23.6$ & $1.3-20.2$ \\
\hline${ }^{156} \mathrm{Gd}$ & $-5.3(0.7)$ & $2.7-6.5$ & 0.0 & 0.2 & 0.0 & 0.5 & 0.6 & 1.4 & 0.3 & 1.1 & $3.3-6.8$ & - & - \\
\hline${ }^{158} \mathrm{Gd}$ & $+8.4(1.1)$ & $0.9-3.3$ & 0.0 & 0.2 & 0.0 & 0.4 & 0.4 & 0.9 & 0.2 & 0.8 & $1.6-3.6$ & - & - \\
\hline${ }^{160} \mathrm{Gd}$ & $-1.2(3.4)$ & $8.6-27$ & 0.0 & 0.0 & 0.0 & 0.4 & 0.4 & 0.8 & 0.2 & 0.6 & $8.7-27$ & - & - \\
\hline
\end{tabular}




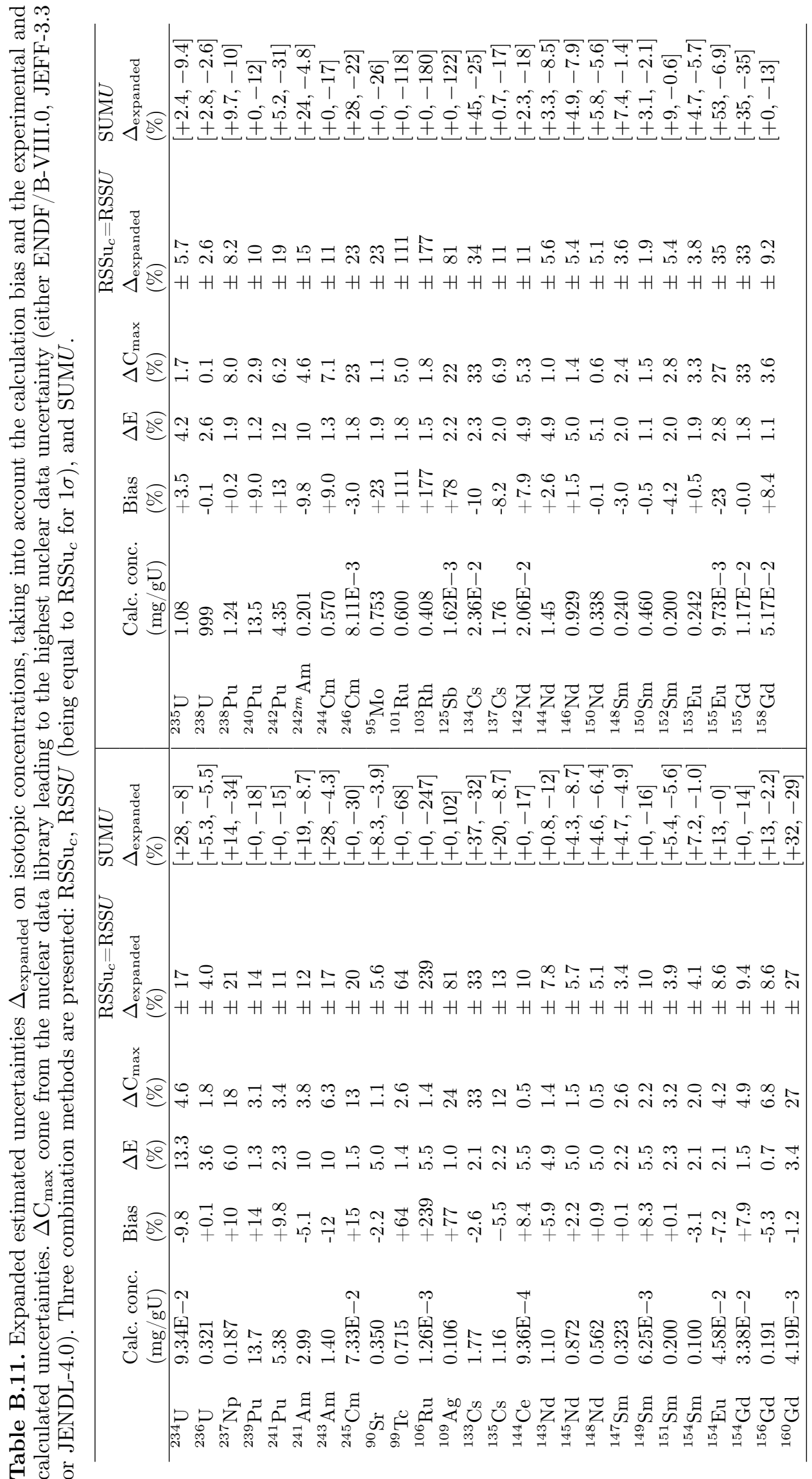


D. Rochman et al.: EPJ Nuclear Sci. Technol. 7, 18 (2021)

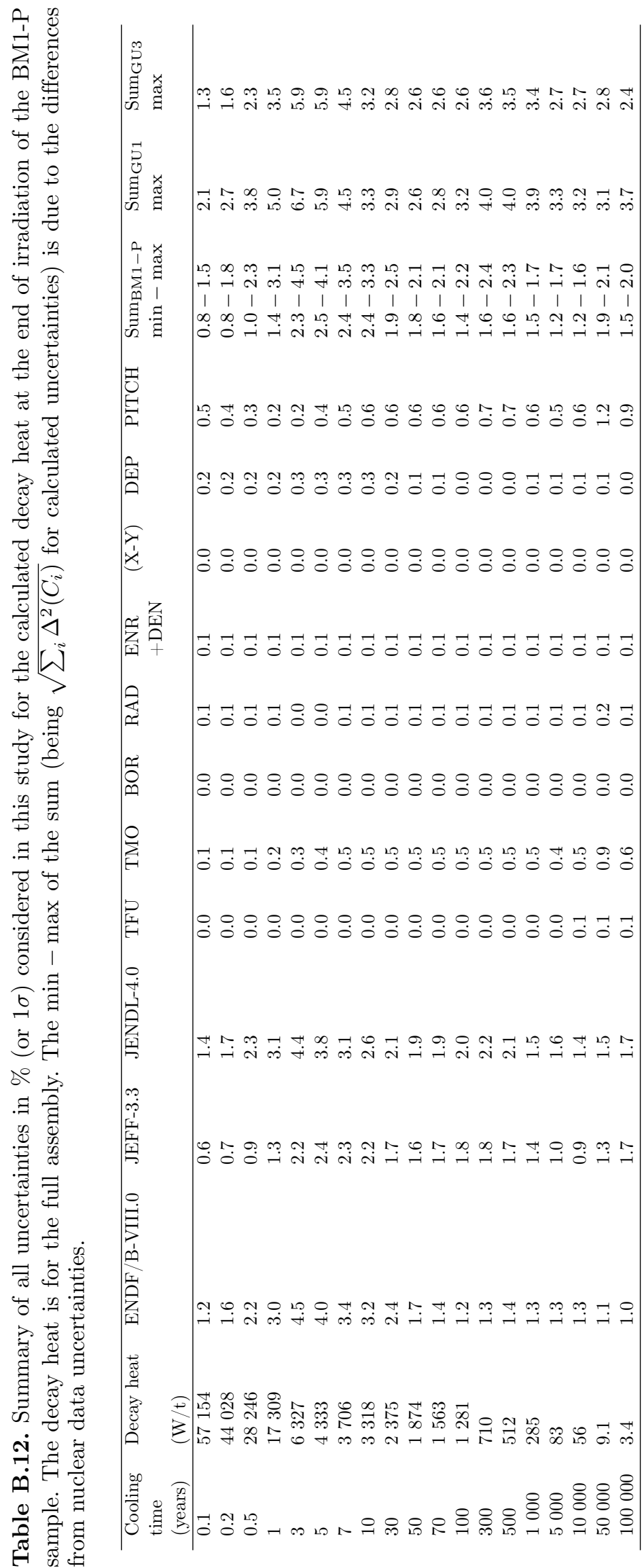




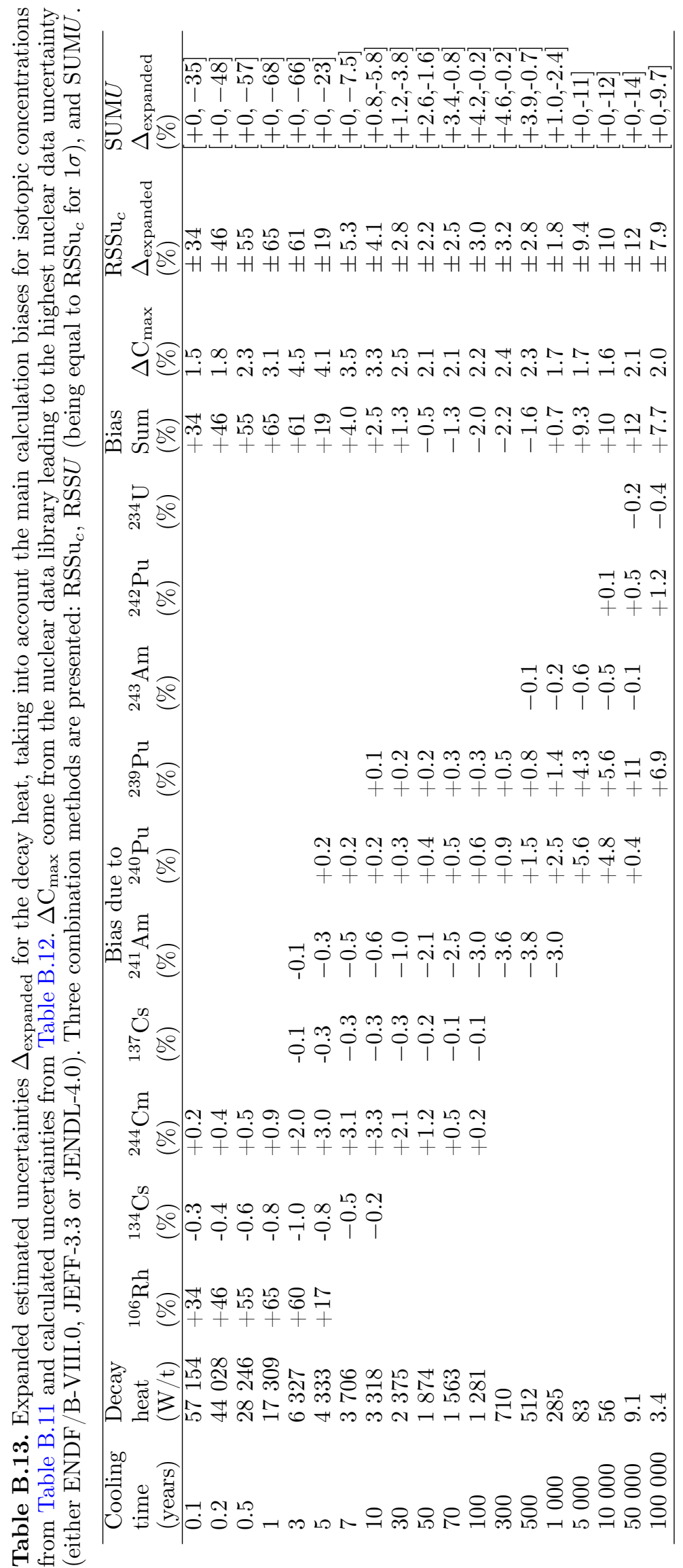

